\title{
Biases in the Mesoscale Prediction of Ceiling and Visibility in Alaska and Their Reduction Using Quantile Matching
}

\author{
James O. Pinto, Dan L. Megenhardt, And Tressa Fowler ${ }^{\mathrm{a}}$ \\ NCAR/RAL, Boulder, Colarado \\ JENNY COLAVITO \\ FAA/AWRP, Washington, D.C.
}

(Manuscript received 19 November 2019, in final form 24 February 2020)

\begin{abstract}
Short-range $(2 \mathrm{~h}$ ) predictions of ceiling and visibility obtained from version 4 of the Rapid Refresh (RAPv4) model are evaluated over Alaska using surface meteorological station data. These forecasts tended to overpredict the frequency of aviation-impacting ceilings in coastal areas by as much as $50 \%$. In winter, this overforecasting bias extends into the interior of Alaska as well. Biases in visibility predictions were more complex. In winter, visibility hazards were predicted too often throughout the interior of Alaska $(+5 \%)$ and not often enough in northern and western coastal areas $(-20 \%)$. This wintertime underprediction of visibility restrictions in coastal areas has been linked to the fact that the visibility diagnostic does not include a treatment for the effect of blowing snow. This, in part, results in winter IFR visibilities being detected only $37 \%$ of the time. An efficient algorithm that uses quantile matching has been implemented to remove mean biases in 2-h predictions of ceiling and visibility. Performance of the algorithm is demonstrated using two 30-day periods (January and June 2019). The calibrated forecasts obtained for the two month-long periods are found to have significantly reduced biases and enhanced skill in capturing flight rules categories for both ceiling and visibility throughout much of Alaska. This technique can be easily extended to other forecast lead times or mesoscale models.
\end{abstract}

\section{Motivation/introduction}

Ceiling and visibility constraints impact aviation safety and efficiency. The Federal Aviation Administration (FAA) has developed a set of rules and regulations for operating aircraft in conditions that are deemed hazardous due to degradation of visibility and/or the presence of low ceiling heights. The flight rules categories are listed in Table 1 with low instrument flight rules (LIFR) being characterized by the most hazardous environmental conditions for aviation. Most general aviation (GA) aircraft are not equipped to fly in either LIFR or instrument flight rule (IFR) conditions. In addition, pilots often let their IFR rating lapse. Thus, few GA flights are properly trained or equipped to fly in IFR conditions. At the same time, GA is a critical means of transportation in Alaska where there is a factor of 16

\footnotetext{
${ }^{a}$ Retired.
}

Corresponding author: James O. Pinto, pinto@ucar.edu more piloted aircraft per capita than any other state in the United States (Klouda et al. 2018). Unfortunately, the surface observing network is relatively sparse due to the large distances between airports and complex terrain that is characteristic of Alaska (Grzywinski and Sims 2005), leaving large voids in the observation of ceiling and visibility needed to inform GA pilot decision making. These issues contribute to the continued incidence of GA accidents in Alaska (Aarons 2018), which motivates the need to improve ceiling and visibility products over Alaska.

A number of techniques have been developed to estimate cloud base height from satellite data. Some of these techniques require coincident surface observations (e.g., Barker et al. 2011) while others are directly retrieved from satellite radiances (e.g., Hutchison et al. 2006; Minnis et al. 2011). More recently developed techniques have improved the accuracy of the cloud base height retrievals from polar-orbiting satellites (Noh et al. 2017); however, the retrieval is only valid for the highest cloud layer and only available a few times per day. Retrievals of surface visibility from satellite data have been developed for clear sky conditions 
TABLE 1. Aviation flight rule categories.

\begin{tabular}{llcc}
\hline \hline Category & \multicolumn{1}{c}{ Definition } & Ceiling $(\mathrm{ft})$ & Visibility $(\mathrm{mi})$ \\
\hline LIFR & Low instrument flight rules & $<500$ & $<1$ \\
IFR & Instrument flight rules & $500-1000$ & $1-3$ \\
MVFR & Marginal visual flight rules & $1000-3000$ & $3-5$ \\
Near-MVFR & Near-MVFR & $3000-5000$ & $5-6$ \\
VFR & Visual flight rules & $>3000$ & $>5$ \\
\hline
\end{tabular}

(e.g., Kessner et al. 2013) and, more recently, conditions in which fog, low clouds and precipitation impacts are included using the latest available imagery from the GOES Advanced Baseline Imager (Brunner et al. 2016). However, remotely sensed quantities obtained by geostationary satellites lose their fidelity poleward of $55^{\circ} \mathrm{N}$ due to distortions in the imagery that result from steeper viewing angles at these latitudes.

In response to gaps in the observing network and the disproportionate number of GA accidents in Alaska caused by ceiling and visibility hazards, the FAA embarked on a program to install web cameras in key locations across Alaska (//avcams.faa.gov/). This program, in concert with other measures, have been widely successful in reducing the number of controlled flight into terrain (CFIT) accidents in Alaska. However, despite these recent advances, CFIT is still a major GA issue in Alaska (Brehmer 2017). Current research sponsored by the FAA and NOAA has focused on improving the analysis and prediction of ceiling and visibility hazards across Alaska. The FAA has sponsored research to estimate visibility from the network of FAA web cameras (e.g., Hallowell et al. 2007; Matthews and Colavito 2017). These efforts to expand the coverage of visibility information across Alaska have been successful; however, the spatial coverage of web cameras is still relatively sparse and retrievals at some camera locations are limited by the spatial distribution of available targets. Similar image processing techniques for estimating ceiling heights are more difficult and have yet to be developed.

Because of the observational limitations listed above for Alaska, numerical weather prediction models and data assimilation systems must be used to generate ceiling and visibility analysis products of sufficient spatiotemporal resolution to support aviation meteorologists, dispatchers and pilots in Alaska. Data assimilation systems offer the advantage of combining a suite of time-varying observations with a model-based first guess field to generate regularly updating analyses of the atmospheric state including clouds and precipitation from which ceiling and visibility can be diagnosed. For example, the Real-Time Mesoscale Analysis (RTMA), described by De Pondeca et al. (2011) uses twodimensional variational data assimilation to produce 3-km analyses of surface air temperature, relative humidity, winds, ceiling heights, and visibility. The Alaska RTMA updates once per hour and uses forecasts from the most recent available High-Resolution Rapid RefreshAlaska (HRRR-AK) forecast as a first guess for each of these parameters. The HRRR-AK runs every $3 \mathrm{~h}$ and assimilates a number of observations including surface observations, soundings, commercial aircraft, NEXRAD radar, and satellite data using a hybrid variational-ensemble approach. (Benjamin et al. 2016; McCorkle et al. 2018).

Biases in the short-term forecast (e.g., 2-4-h lead times) of the first guess fields obtained from HRRR-AK can influence the performance of RTMA Alaska. In some cases, when biases in the first guess field are large, differences between the model and the observations (a.k.a. innovations) may be so large that the influence of the observations may be small or even rejected. Thus, methods devised to reduce biases in the first guess fields could help to improve analyses of ceiling and visibility produced by variational analyses like RTMA.

Various methods have been used to bias correct model forecast data by relating model forecast variables to observed quantities. Model output statistics (MOS) approaches have been developed over the years to derive quantities from model forecast data using a series of regression equations (Glahn and Lowry 1972) and, more recently, to derive aviation specific weather hazard products, (e.g., ceiling heights and visibility) from model data as is done in version of the Localized Aviation MOS Program (LAMP; Ghirardelli and Glahn 2010; Glahn et al. 2017). The output from these types of regression-based techniques for ceiling and visibility are probabilistic categorical (i.e., defined by a range of values) rather than providing the full continuum of actual values. A postprocessing step is then often used to pick the best category (e.g., Weiss and Ghirardelli 2005). In addition, these technique work best when long training datasets are available during which model formulations have not been changing. The current state of rapid model development cycles makes it difficult to maintain stable regression relationships between model forecasted fields and observations, especially for the diagnosis of infrequently occurring events (e.g., LIFR 
conditions). Machine learning (e.g., Rasp and Lerch 2018) and analog ensemble (e.g., Delle Monache et al. 2011) techniques have also been shown to be effective in developing relationships between model data and observations, but require a long period of consistent model data. Hopson and Webster (2010) used a quantile matching technique to remove bias from rain rate forecasts obtained from a global ensemble model as part of a flood forecasting system. A key aspect of quantile matching is that it provides a continuum of ceiling and visibility values (rather than categories). In addition, this method preserves the spatial and temporal (ranked) covariances of the forecast field, which is critical for preserving the structure of discontinuous fields like ceiling and visibility.

In this study, we explore the value of using the Hopson and Webster (2010) method to reduce mean biases in short-term predictions of ceiling and visibility obtained with an operational mesoscale model. Datasets used in this study and model biases are described in sections 2 and 3, respectively. This is followed by a description of the bias-correction technique and how it performs for RAPv4 predictions of both ceiling and visibility over Alaska in sections 4 and 5. Finally, closing remarks and an outlook for the future are given in section 6 .

\section{Dataset descriptions}

Data from surface meteorological stations distributed across Alaska and the NCEP RAPv4 model are used to evaluate the quantile matching calibration algorithm. RAPv4 model data and surface meteorological stations are obtained from the Local Data Manager (LDM) feed provided by Unidata. Details of each dataset are given below.

Version 4 of the RAP modeling system was implemented into operations at NCEP in 2018. The RAP model uses version 3.8.1 of the Weather Research and Forecasting (WRF) Model (Skamarock and Klemp 2008; Skamarock et al. 2008) plus additional physics changes as described by Alexander et al. (2018). The RAP forecast system includes state-of-the-art data assimilation of a long list of observational datasets using hourly cycling and a hybrid ensemble/3D variational approach within their Gridpoint Statistical Interpolation (GSI) framework (Benjamin et al. 2016). Forecast products from the RAP model, which are computed using the Unified Post-Processor $\left(\mathrm{UPP}^{1}\right)$, have been used for many years by aviation meteorologists in Alaska to

\footnotetext{
${ }^{1}$ https://dtcenter.org/community-code/unified-post-processorupp/upp-user-release-version-4-0-1.
}

provide forecast support for aviation operations. More recently, a HRRR model nest was implemented over Alaska (HRRR-AK). This new nest, which is driven by the RAP model, has begun to provide finer-resolution guidance. This study focuses on evaluation and improvement of RAPv4 since this forecast system has been available over Alaska for many years. Both ceiling and visibility are derived from variables that are explicitly predicted by the model as described below. This study focuses on 2-h forecasts, since this is the nominal lead time used as a first guess field by data assimilation system such as RTMA Alaska.

As mentioned above, the UPP is used to diagnose ceiling and visibility heights from the RAPv4 model output. The ceiling height is determined via a sequence of steps. The first step is to find the first model level above the surface where the predicted cloud water (liquid + ice) content exceeds $10^{-6} \mathrm{~kg} \mathrm{~kg}^{-1}$. This initially determined cloud base height is lowered if the vertical visibility computed from the snow water mixing ratio at the lowest model level is less than the cloud base that was determined using the $10^{-6} \mathrm{~kg} \mathrm{~kg}^{-1}$ threshold. In addition to this criterion, a cloud base is diagnosed in areas where the relative humidity at the top of the boundary layer exceeds $95 \%$ regardless of whether or not any cloud water is present. Next, if the base of convective clouds is lower than that of the explicitly determined cloud base, then the convective cloud base is used as the cloud base. Finally, to avoid identifying surface-based fog layers as low ceilings, instances in which only the two lowest model levels (i.e., below $80 \mathrm{~m}$ AGL) contain cloud water exceeding $10^{-6} \mathrm{~kg} \mathrm{~kg}^{-1}$ are not given a ceiling height. Once the cloud base is determined, a ceiling is diagnosed as the height of the first model level above the surface where the cloud fraction (as determined within the radiation scheme) exceeds $50 \%$.

The visibility diagnostic used in the UPP was adapted from Stoelinga and Warner (1999). The visibility is a function of the horizontal extinction due to the presence of cloud ice, cloud water, rain, snow and graupel in the lowest three model levels. If no hydrometeors are present then the visibility is a function of relative humidity following Keller and Kuchera (2004),; however, $\mathrm{RH}$ alone can only reduce visibility down to $12 \mathrm{~km}$. Visibility at night (based on distance a point source of light can be seen) is computed following Rasmussen et al. $(1999)^{2}$ resulting in higher visibilities at night than during the day for a given amount of condensed water. While the impact of aerosols on visibility is currently not considered, the next release of the RAPv5 (planned for

\footnotetext{
${ }^{2}$ https://rapidrefresh.noaa.gov/RAP_var_diagnosis.html.
} 

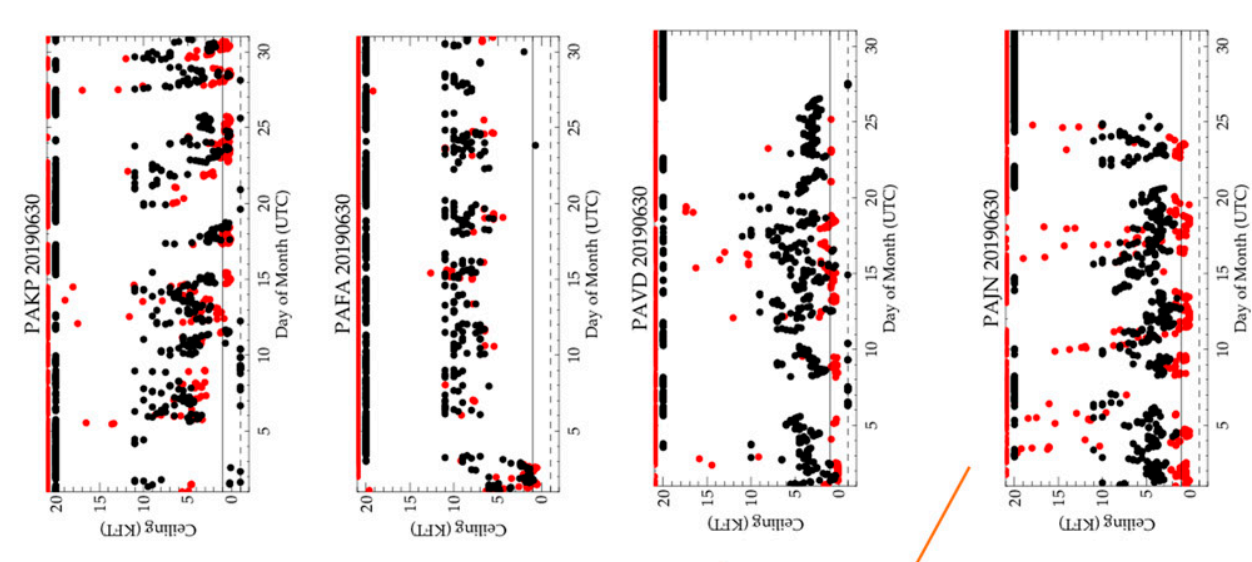

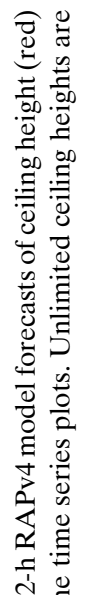
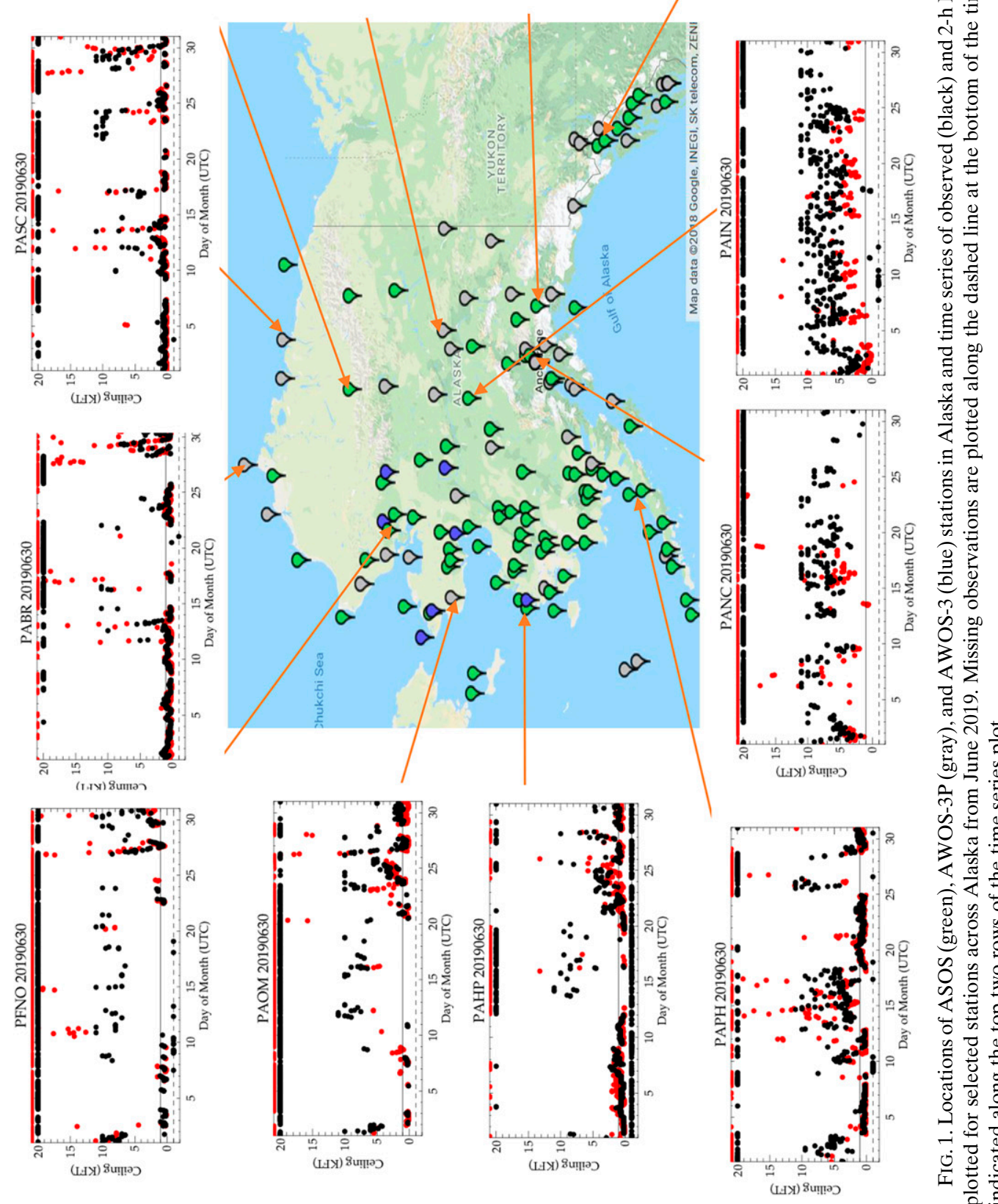

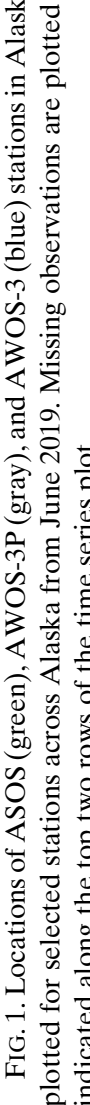


release in 2020) will include a treatment of the impact of smoke from wildfires on horizontal visibility (James et al. 2019).

Automated measurements of ceiling and visibility are available from surface meteorological stations located at airports across Alaska as shown in Fig. 1. These stations are a mixture of ASOS, AWOS-3, AWOS-3P, and SAWRS that are maintained by the FAA, NWS, U.S. Army, and private entities. ${ }^{3}$ For simplicity we refer to these stations as surface met stations, hereafter.

Each surface met station is equipped with sensors to measure both ceiling and visibility. Visibility is derived from locally measured light extinction across a small volume of air using a system developed by Belfort. The amount of pulsed blue light that is scattered out of a $0.75-\mathrm{ft}^{3}$ volume of air is measured to determine an extinction coefficient. The amount of scattering is a function of atmospheric constituents (e.g., relative humidity, condensed water, ice, and aerosol) that are primarily responsible for impacting visibility (NWS 1998). The extinction values are converted to visibility in miles using empirical relationships for daytime and night time conditions as described by Rasmussen et al. (1999). Generally, visibility measurements obtained with this system have been found to be within $20 \%$ of the actual visibility as identified by a human observer (Crosby 2003). Compiling statistics from all 160 stations that were available (see station locations in Fig. 1), it was found that visibility restrictions were more common in January (19\%) than June 2019 (8\%) across Alaska (Table 2).

Cloud fraction and cloud base height (or ceiling) are measured using a laser ceilometer (Vaisala models CT12K or CL31). The ceilometer collects backscatter samples every $30 \mathrm{~s}$. The 30 -min history of this data is used to determine cloud fraction and ceiling height with the last $10 \mathrm{~min}$ being weighted double. Up to three distinct cloud layers may be detected. For each layer, the cloud amount is estimated from the ratio of the number of cloud detections to the total number of 30 -s samples in the last $30 \mathrm{~min}$. The cloud fraction bins $(5 \%-25 \%$, $25 \%-50 \%, 50 \%-87 \%$, and $87 \%-100 \%$ ) are converted to cloud amounts few (FEW), scattered (SCT), broken (BKN), and overcast (OVC), respectively (NWS 1998). For the purposed of this study, and in accordance with the Federal Meteorological Handbook (NOAA 2017), the observed ceiling height is defined as the height of the lowest cloud layer that is classified as either BKN or OVC. When the cloud base is completely obscured by precipitation or fog, the ceiling is reported as a vertical

\footnotetext{
${ }^{3}$ https://www.faa.gov/air_traffic/weather/asos/.
}

TABLE 2. Observed frequencies in 2019 of occurrence from all surface met stations; $N=$ number of stations with outages less than 1 week out of 160 total.

\begin{tabular}{lcccc}
\hline \hline Month & LIFR + IFR & MVFR & VFR & $N$ \\
\hline \multirow{5}{*}{ January } & 0.1347 & Visibility & \\
June & 0.0534 & 0.0525 & 0.8127 & 107 \\
& & Ceiling & & 106 \\
January & 0.1025 & 0.2094 & 0.6882 & 108 \\
June & 0.1208 & 0.1233 & 0.7559 & 107 \\
\hline
\end{tabular}

visibility (VV) instead of a cloud-base height. As in An et al. (2017), cases in which the ceiling height is classified as "VV" are included in this study. Using these criteria, and compiling values across all stations, it was found that restrictive ceilings were observed more often in January (31\%) than June (24\%) 2019 with notably more MVFR ceiling heights occurring in January (Table 2).

The spatiotemporal variability in ceiling heights is evident in time series of data collected during June 2019 (Fig. 1). The observations were matched in time with the model valid times by selecting surface met station reports that were closest to the top of the valid hour and enforcing a maximum offset of $\pm 15 \mathrm{~min}$. The character of the observed ceiling heights varies dramatically across Alaska. Coastal areas generally experience more frequent low cloudiness than interior Alaska with the greatest frequencies being found in coastal regions of the North Slope [e.g., Utqiagvik (PABR)]. Southwestern Alaska [e.g., Hooper Bay (PAHP)] also experienced a great deal of low cloudiness in June 2019, while skies at Anchorage (e.g., PANC) were relatively free of low clouds. Interior regions of Alaska [e.g., Fairbanks (PAFA)] generally had less cloud cover and far fewer ceiling restrictions than coastal regions in June 2019. The model captures these regional variations in ceiling height as well as specific ceiling restricting events at each station. Long-duration, low ceiling events are evident at many of the coastal stations. The model captures most of the long-duration, low ceiling height (i.e., IFR) events (e.g., PABR) but has more difficulty representing the shorter-duration MVFR conditions (e.g., PANC). At many of the stations, the modeled ceiling heights tend to be too low. This leads to a number of the observed MVFR events being predicted as IFR [e.g., Anaktuvuk (PAKP), Valdez (PAVD), and Juneau (PAJN)]. Note that part of this tendency to predict lower ceilings than observed at these three stations is due to differences between the station elevation and the terrain height of the model grid point used to make these comparisons. This will be discussed further below. 

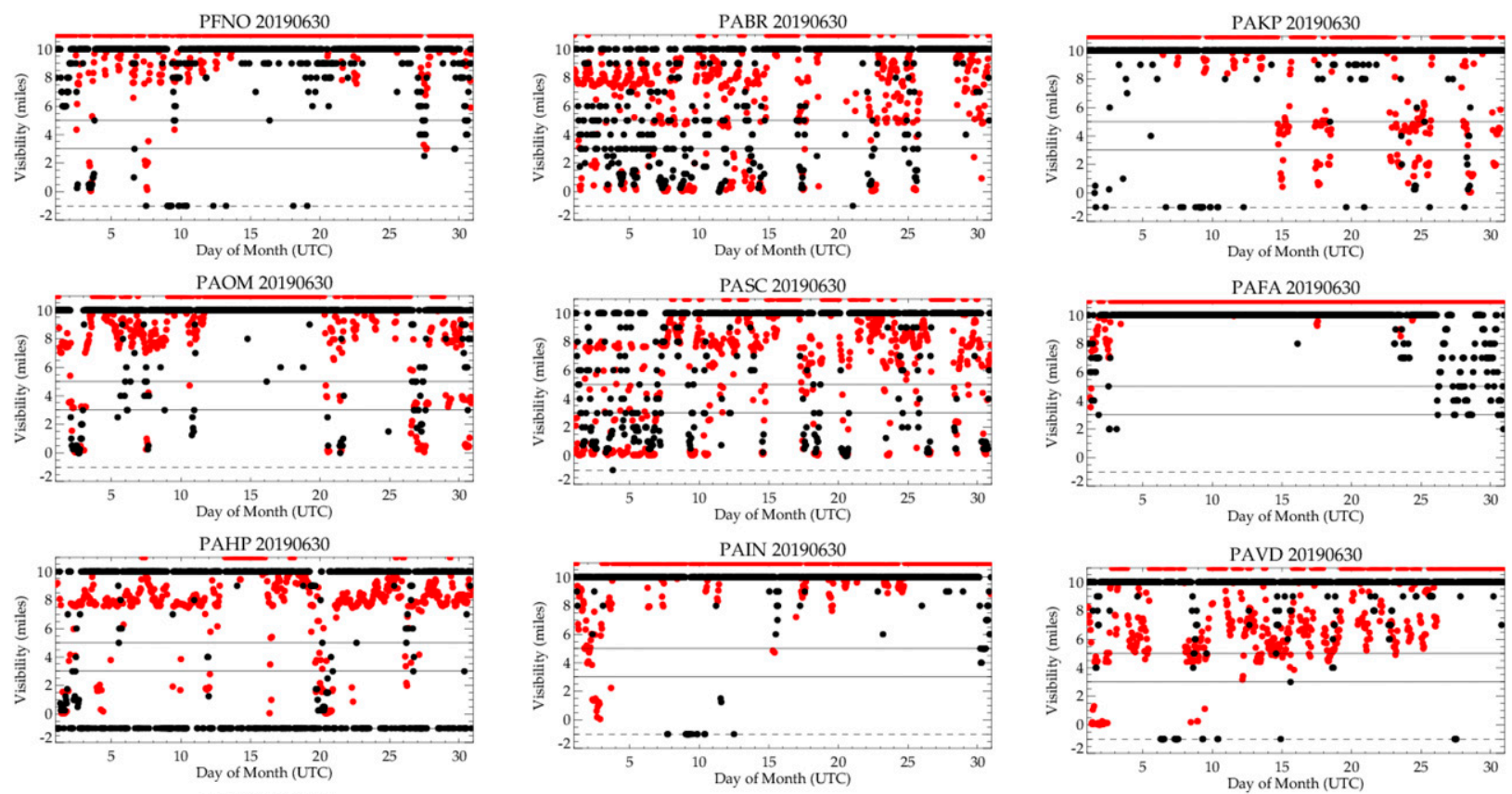

PAPH 20190630
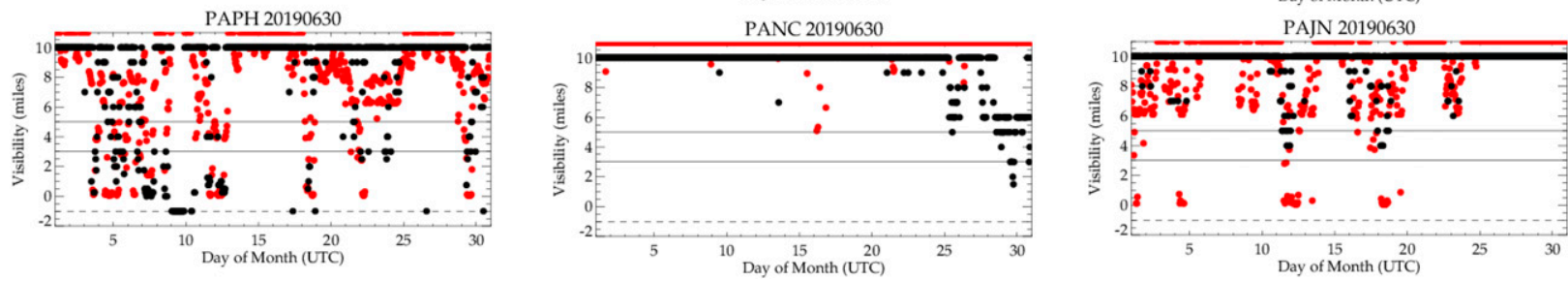

FIG. 2. Time series of 2-h RAPv4 forecasted (red) and observed (black) visibility for same set of stations shown in Fig. 1 for June 2019. Missing observations are plotted along the dashed line at the bottom of the time series plots. Unlimited visibilities are indicated along the top two rows of the time series plot.

Time series of visibility observations and RAPv4 forecasts are shown in Fig. 2 for June 2019. While the visibility time series are more noisy than those obtained for ceiling heights, regional variations in the frequency of visibility- and ceiling-restricting events are broadly similar. Like that found for IFR ceiling heights, IFR visibilities restrictions (i.e., $<3$ miles) tend to be most common at coastal stations and less common in the interior of Alaska. As with ceiling heights, the model captures some of the observed visibility-impacting events (e.g., see PABR, PAHP), but there are more false alarms (e.g., PAKP and PAJN) and misses [e.g., PABR, Deadhorse (PASC)] than were evident in the ceiling height comparisons. Additional misses are evident at two interior Alaska stations (PAFA and PANC) at the end of June that have been traced back to the presence of smoke produced by wildfires, which the RAPv4 does not handle.

Data availability fluctuates with time at each observing station. Of the 160 stations providing surface observation reports, more than 50 experienced outages totaling more than one 1 week in both months (Table 2). The surface met station located at Hooper Bay, Alaska (PAHP), provides an example of intermittent outages that total more than a week over the course of the month of June. These outages reduce the sample size, which will locally impair the performance of the calibration algorithm.

\section{Model biases}

The time series data described above is used to compute the frequency of occurrence of aviation-impacting ceilings and visibilities across Alaska from both surface met observations and the RAPv4 model. Spatial and seasonal variability in IFR conditions is evident in both model and observation datasets (Figs. 3 and 4). Generally, both model and surface met observation data indicate that the frequency of IFR conditions is greater in coastal regions than the interior and greater in summer than in winter. The modeled frequencies provide important details in the spatial variability of IFR conditions that 

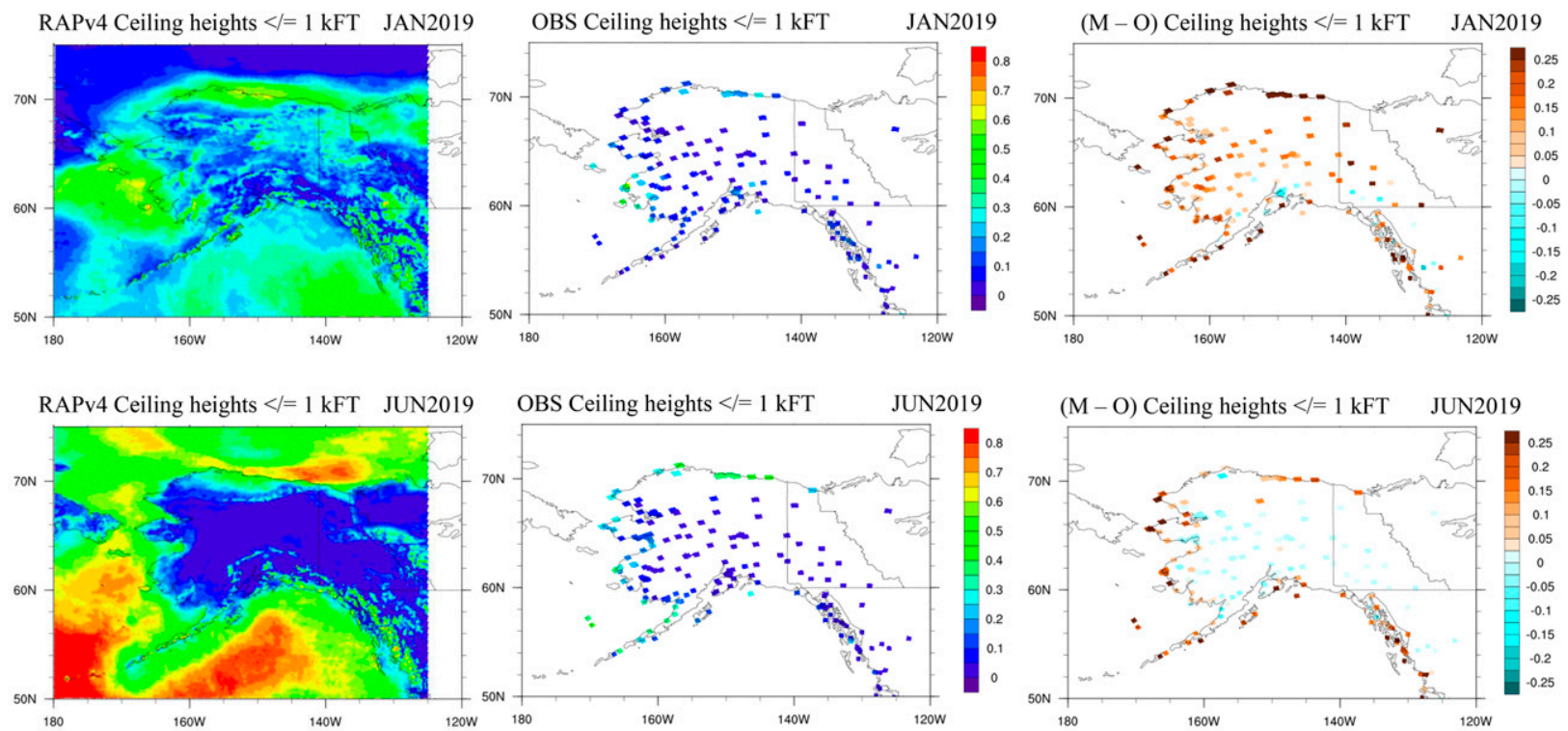

FIG. 3. Frequency of ceiling heights of $1000 \mathrm{ft}$ or less from (left) RAPV4 2-h forecasts and (center) surface met stations along with (right) the frequency bias $(M-O)$ at each surface met station site for (top) January and (bottom) June 2019.

cannot be resolved by the surface observing network. For example, in both seasons, the model indicates that IFR ceilings found in coastal regions extend inland to varying degrees across Alaska, with IFR ceilings extending well inland along the North Slope. Additional details reveal plausibly enhanced frequencies of IFR conditions (both ceiling and visibility) that are coincident with mountain ranges throughout Alaska. The model also indicates peak frequencies of low clouds occurring over coastal waters and open ocean areas. Unfortunately, observations are generally limited over the ocean except for a few island-based surface met stations. Observations obtained from surface met stations on the Aleutian Islands reveal that data assimilation locally reduces the frequency of low ceilings and visibilities (especially evident in June-see
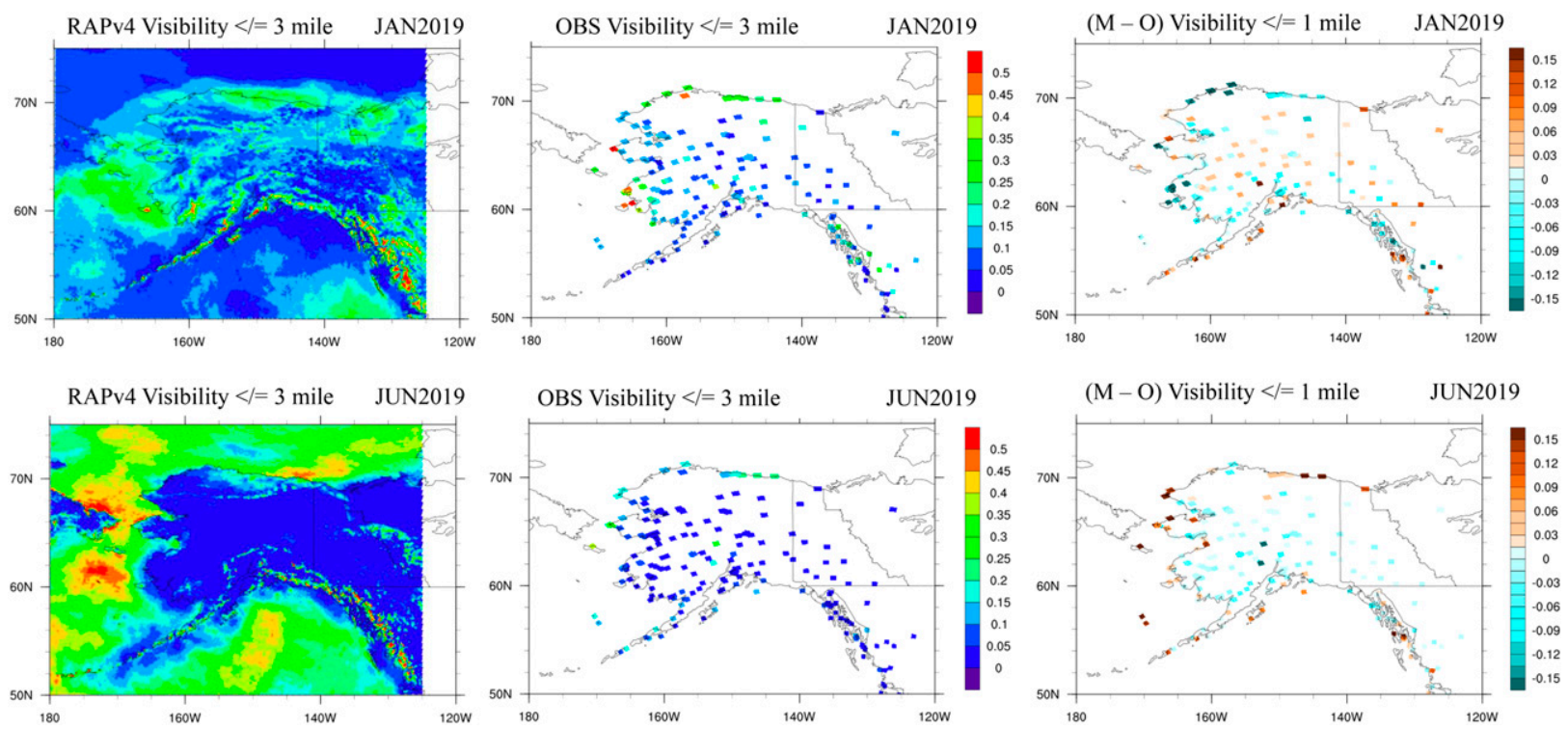

FIG. 4. Frequency of visibility of $3 \mathrm{mi}$ or less from (left) RAPv4 2-h forecasts and (center) surface met station along with (right) the difference or bias $(M-O)$ at each surface met station site for (top) January and (bottom) June 2019. 
Fig. 4) indicating that oceanic areas far removed from the influence of assimilated surface observations are likely to overestimate the frequency of low ceilings and visibilities.

Differences between the modeled and observed frequency of IFR conditions are also shown in Figs. 3 and 4. A general tendency of the model to predict IFR ceilings too often is event in both January and June with this bias being more widespread in January and confined to coastal areas in June (Fig. 3). In both seasons the ceiling height frequency bias is largest $(+0.25)$ in coastal areas. The maximum bias shifts from stations along the North Slope of Alaska in January to stations along the west coast of Alaska in June. Conversely, the model tended to slightly $(-0.05)$ underforecast the frequency of low ceilings throughout much of interior Alaska in June. Also, it is important to note that despite the reduced frequencies of low ceiling over the Aleutians in June, there is still a tendency for the model to overpredict the frequency of IFR conditions.

The frequency of observed IFR visibilities (less than $3 \mathrm{mi}$ ) is quite low throughout much of Alaska (Fig. 4). Low visibilities are most common in winter in coastal areas and mountain passes (though a limited number of stations are available in mountain passes). Seasonal variation in observed IFR visibility are evident in coastal areas along the North Slope and western coastal areas. The model indicates that the frequency of IFR visibilities changes dramatically with season over oceanic areas with frequencies increasing from near zero in winter to over $25 \%$ in summer. The opposite is true in the interior of Alaska, where the frequency of IFR events varies from $20 \%$ in winter to near zero percent in summer. The model data also shows elevated frequencies of visibility less than $3 \mathrm{mi}$ over mountainous regions in both seasons. The model tended to underforecast the frequency of IFR visibilities in coastal areas and overforecast the frequency of occurrence in the interior of Alaska in winter while the opposite was true in the summer.

The analysis described above indicates that both ceiling and visibility forecasts from RAPv4 have biases that vary notably with region and season. The analyses also indicate that, while assimilation in RAPv4 reduces the overforecasting bias in the IFR ceilings and visibilities in regions dominated by oceanic influence, significant biases remain. In the following sections we describe the implementation of a quantile matching calibration algorithm and demonstrate its utility in reducing forecast bias and improving model skill. Specific examples of the performance of the algorithm are

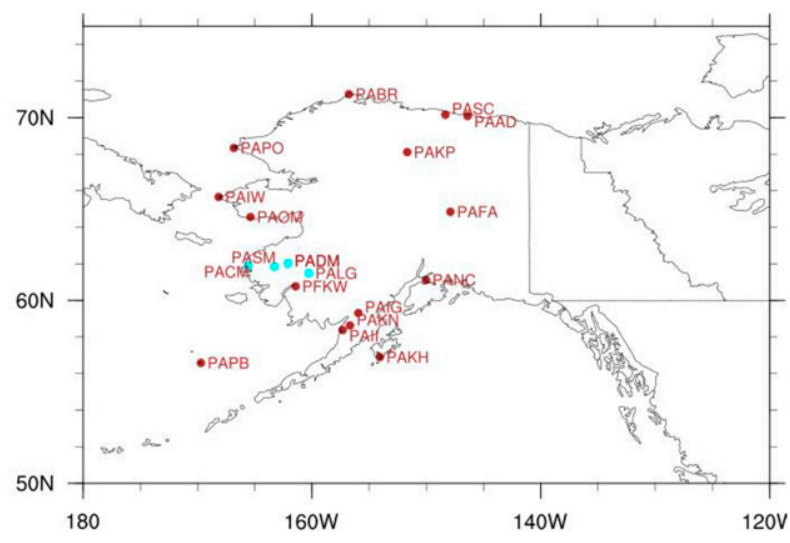

FIG. 5. Map of surface met station locations referred to in the text. Cyan dots denote stations along transect used in Fig. 8.

discussed for several of the station locations shown in Fig. 5.

\section{Bias correction methodology}

The quantile matching method technique described by Hopson and Webster (2010) has been implemented to reduce biases in 2-h forecasts of ceiling and visibility obtained from RAPv4. Note that this technique could be applied to any forecast leadtime of interest. The quantile matching technique utilizes comparisons between cumulative density functions (CDF) obtained from both the model and observations of ceiling and visibility. The CDFs are built using only times when both model and observation data are available. A key consideration is the length of time used to collect data to build the CDFs. The data collection period needs to be long enough to have enough events within each flight rule category, while at the same time, remaining short enough to capture seasonal variability in the biases. The number of samples available varies by station due to the occurrence of data outages. It was found that using a data collection period of 30 days provided an adequate number of valid observation-model pairs at most surface met stations.

Examples of modeled and observed CDFs obtained using data collected at two surface met stations located in northern Alaska are shown in Fig. 6. To reduce storage needs and promote scalability with the number of surface met stations, the CDFs are defined using a discrete set of thresholds for which the percentiles values are stored. The threshold values used to define the CDFs for both ceiling heights and visibility are indicated by the filled circles. The CDFs shown for ceiling height for PABR and PAKP 

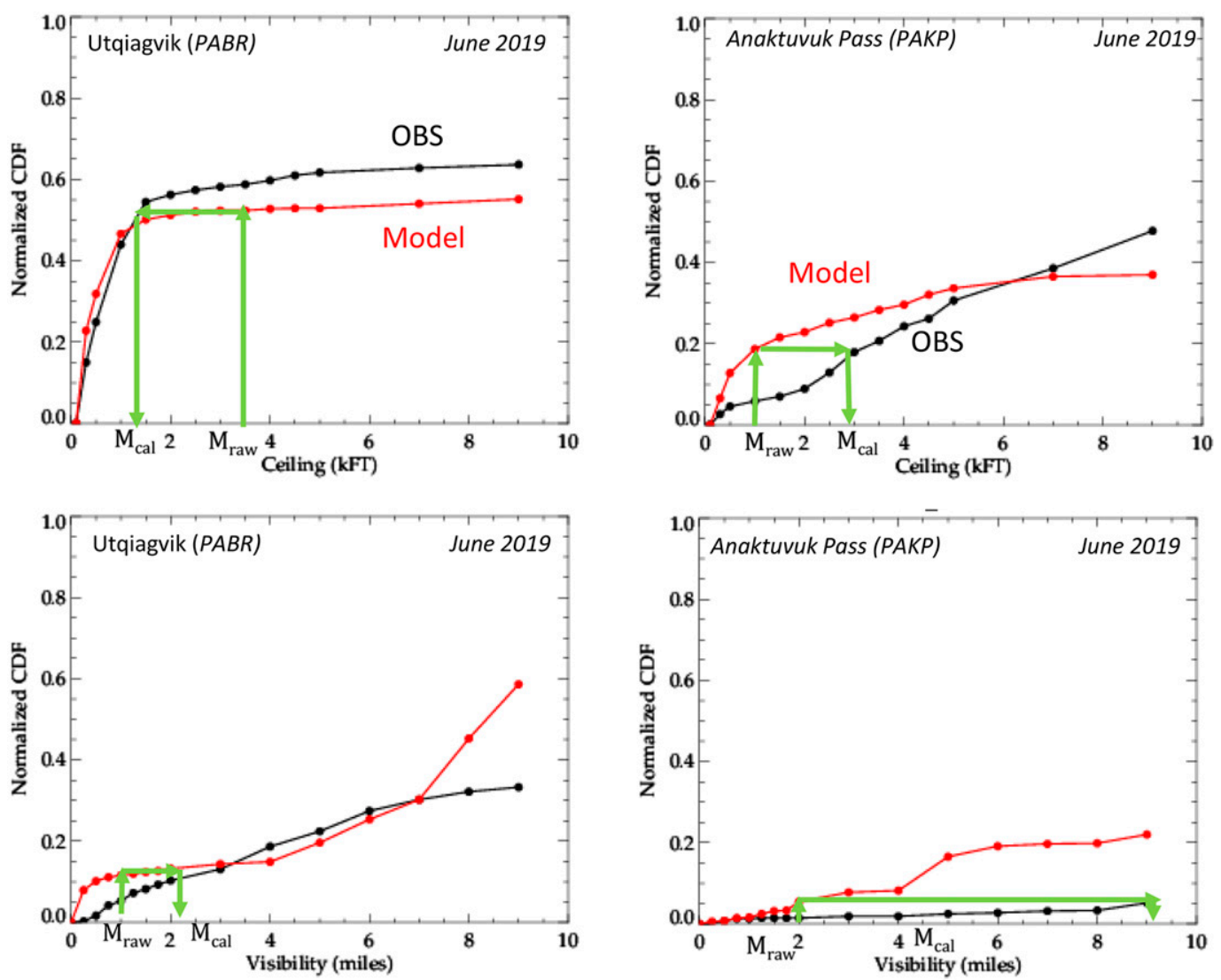

FIG. 6. Cumulative frequency distributions for (top) ceiling height and (bottom) visibility obtained at (left) Utqiagvik and (right) Anaktuvuk Pass as obtained from surface met stations (black) and extracted from the nearest RAPv4 model grid point (red) for June 2019. Green arrows provide examples of the calibration method. See text for details.

demonstrate two different model bias relationships. At PABR, the frequency of IFR ceilings (i.e., $<1000 \mathrm{ft}$ ) is well captured, while the frequency of MVFR ceiling (i.e., 1000-3000 ft) is underforecasted. At PAKP, the frequency of both IFR and MVFR ceilings is overforecasted.

A schematic representation of the calibration technique is denoted by the green arrows in Fig. 6 . The first step is to find the frequency of occurrence of the raw (uncalibrated) model forecast (Mraw). At PABR, a raw ceiling height forecast of $3500 \mathrm{ft}$ is at the $53 \mathrm{rd}$ percentile of all recent past forecasts. The 53rd percentile corresponds with an observed ceiling height that falls between 1000 and $1500 \mathrm{ft}$. Linear interpolation is used to find the corresponding observed ceiling height value of $1300 \mathrm{ft}$. By reducing the ceiling height at PABR from 3500 to $1300 \mathrm{ft}$, the calibration technique, in effect, increases the frequency of MVFR ceilings. The inverse of this is demonstrated at PAKP where the model tends to predict low ceilings too often. In this example, the raw model value of $1000 \mathrm{ft}$ (20th percentile) corresponds with and observed ceiling height of $3000 \mathrm{ft}$. Thus, in this example, ceiling height would be increased.

Visibilities are corrected in the same way; however, low visibilities occur much less frequently than low ceilings at these two sites (and across Alaska-see Table 2, Figs. 3 and 4). For example, IFR visibilities (ceilings) are observed only $13 \%(42 \%)$ of the time at PABR and $1 \%(5 \%)$ of the time at PAKP. At PABR, LIFR visibilities (less than $1 \mathrm{mi}$ ) are predicted too often while the frequency of visibilities of 3 mi or more is relatively unbiased (Fig. 6). Thus, for PABR, a raw model visibility of $1 \mathrm{mi}$ would be increased to over $2 \mathrm{mi}$ to reduce the overforecasting bias. At PAKP, the cumulative frequency of modeled visibilities is greater than the observed cumulative frequency at all thresholds indicating an overforecasting bias. In fact, in the example shown, a raw value of $2 \mathrm{mi}$ corresponds with an observed value of over $9 \mathrm{mi}$.

The last example described above demonstrates a limitation of the calibration algorithm and points to 
a) Ceiling $=1 \mathrm{kFT}$

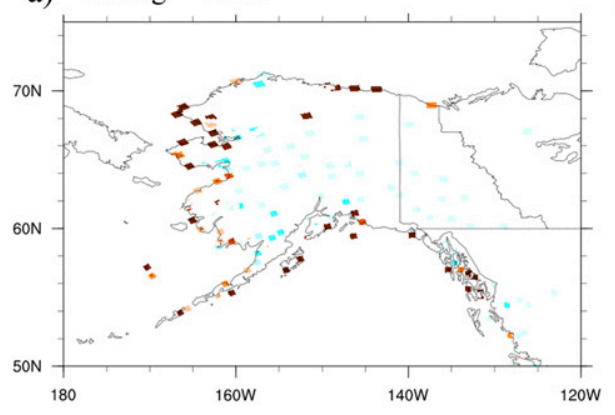

Visibility $=3$ mile

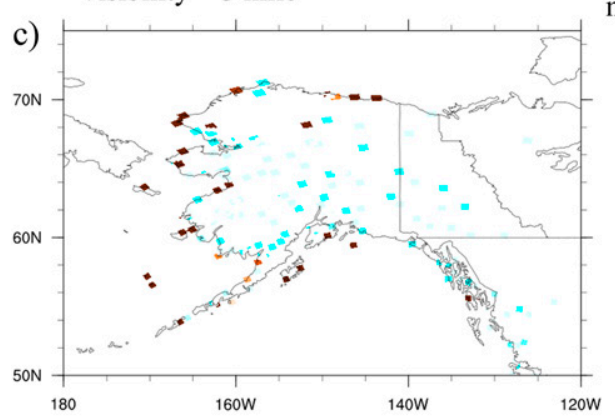

kft

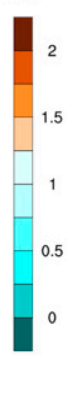

miles

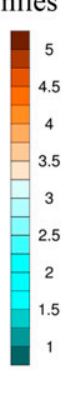

b) Ceiling $=1 \mathrm{kFT}$

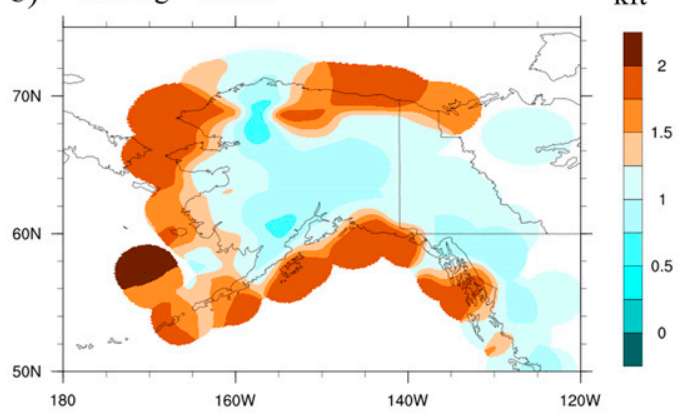

Visibility $=3$ mile

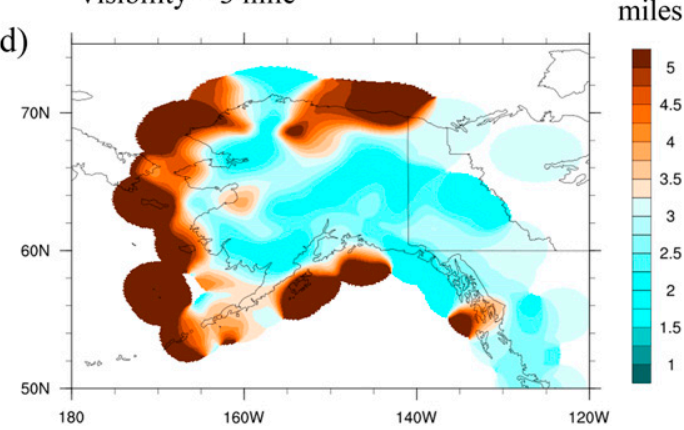

FIG. 7. Maps of calibration value for (a) ceiling heights of $1000 \mathrm{ft}$ and (c) visibility of $3 \mathrm{mi}$ computed using 30 days of data from June 2019 for individual surface station locations and calibration maps obtained using a distance-weighted averaging and a radius of influence of $200 \mathrm{~km}$ for (b) 1000-ft ceiling heights and (d) 3-mi visibility.

the need for using upper and lower limits to the magnitude of the calibration in order to avoid overfitting. As such, restrictions have been set to limit the magnitude of the calibration to be no less than $50 \%$ and no more than $200 \%$ of the raw values. Thus, in the example for ceiling height calibration at $\mathrm{PABR}$, the raw value of $3500 \mathrm{ft}$ will only be reduced to calibrated value of $1750 \mathrm{ft}$ since the full calibration value of $1300 \mathrm{ft}$ is below the $50 \%$ limit while at PAKP the calibrated visibility value would only be increased to $4 \mathrm{mi}$ (rather than $9 \mathrm{mi}$ ) since the initial calibrated value exceeds the $200 \%$ limit. It should be noted that the calibration procedure only works for cases in which the model has some indication of a visibility- or ceiling-restricting event. That is, the calibration algorithm cannot produce an event occurrence if there is no indicator of an event in the raw model data.

Using the technique described above, calibrated values are found for each station across Alaska for the full set of thresholds shown in Fig. 6. The corresponding calibrated ceiling and visibility values for a single raw value (1000 ft and $3 \mathrm{mi}$, respectively) are shown Fig. 7. For a raw model ceiling value of $1000 \mathrm{ft}$, the corresponding calibrated values range from $750 \mathrm{ft}$ (interior Alaska) to nearly $2000 \mathrm{ft}$ (coastal regions). The calibrated ceiling values less than $1000 \mathrm{ft}$ are used to offset an underforecasting bias while values greater than $1000 \mathrm{ft}$ will offset predictions of too much low cloud. A similar pattern is evident in the calibrated visibility field for a raw value of $3 \mathrm{mi}$ with the largest calibrated values being found in the coastal regions.

The calibrated values are spread spatially using distanceweighted averaging:

$$
F_{\text {cal }}=\sum_{i=1}^{n \text { station }} w_{i} F_{\text {cal }_{i}} / \sum_{i=1}^{n \text { station }} w_{i}
$$

where $F_{\mathrm{cal}_{i}}$ are the calibrated values obtained at each station located within $200 \mathrm{~km}$ of a given model grid point (closest grid point to each surface met station) and the weight is given by $w_{i}=\min \left[1,\left(D_{s}-D_{i}\right) / 150\right]$, where $D_{i}$ is the distance between the current model grid point and each of the $i$ stations within a search radius distance $D_{s}(=200 \mathrm{~km})$. The final grid of $F_{\text {cal }}$ values is then smoothed using a $6 \times 6$ gridpoint box car average.

The $200-\mathrm{km}$ scale was selected in order to spread the calibration values obtained for each station across 

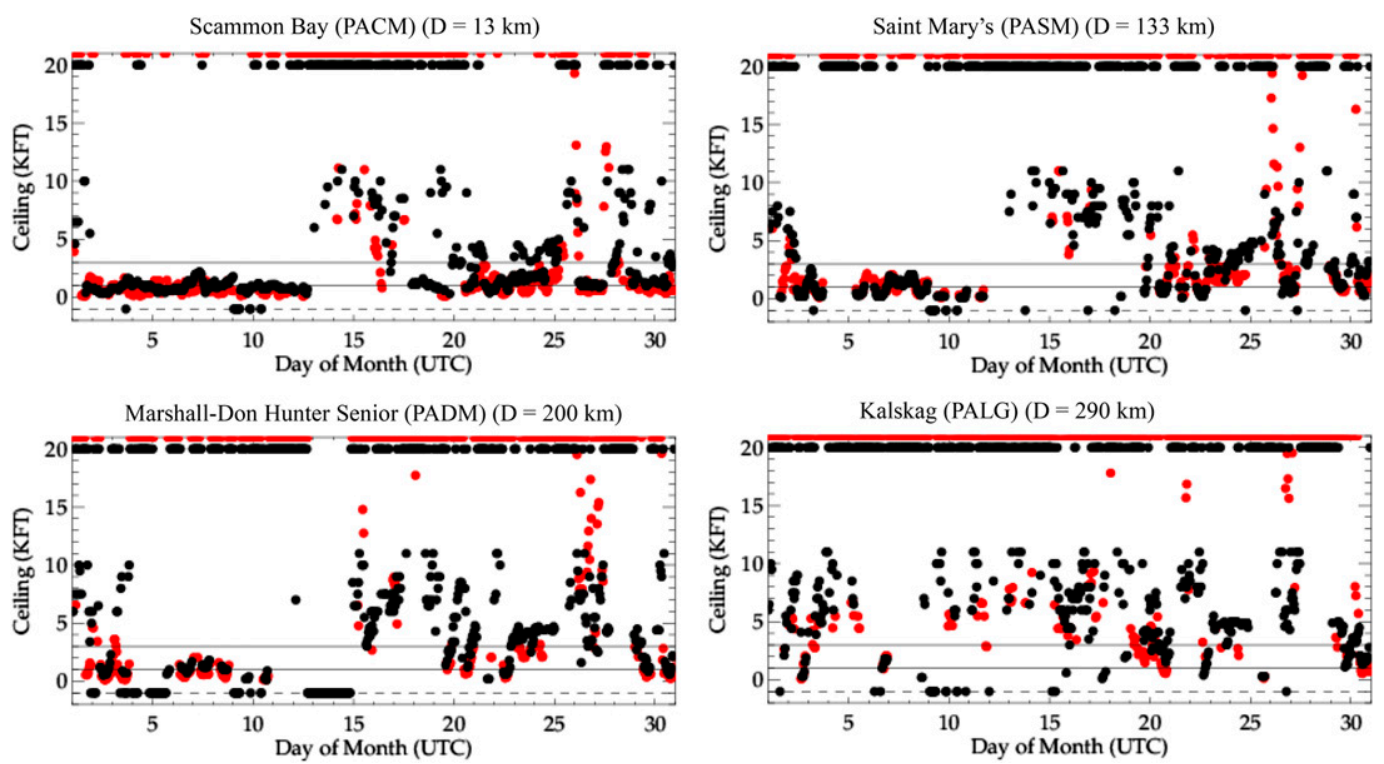

FIG. 8. Time series of modeled (red) and observed (black) ceiling height from four stations in the Yukon Delta region as denoted by cyan color dots in Fig. 5. The distance from the coast $D$ is given at the top of each panel. Data are from June 2019. Missing observation data points are indicated along the dashed line at the bottom of each plot.

the entire state without any gaps. This radius of influence is similar to that suggested by Glahn and Im (2011) to use as a first pass for producing objective analyses from surface met station data. This scale was found to work reasonably well for Alaska because it matched the scale over which climate regimes transitioned from coastal to interior. This transition zone is demonstrated by the change in the character of ceiling heights with distance inland over the Yukon Delta region of southwestern Alaska (Fig. 8). Over a distance of roughly $200 \mathrm{~km}$ (see Fig. 5 for station locations), the character of both the modeled and observed ceiling heights changes from long-lived IFR ceiling heights (coastal) to more elevated cloud layers and less frequent IFR ceiling restrictions (interior). Stations at St. Mary's (PASM) and Marshall (PADM) represent conditions in the transition zone (130-200 km from the coast) while PALG is more representative of interior Alaska. In a series of sensitivity tests it was found that using a distance-weighted average of between 100 and $200 \mathrm{~km}$ produced the best results while the worst results were obtained using a search radius of zero (not shown).

The calibration is applied by calculating a weighted average of the raw model forecasted value and the calibrated value obtained using the method described above. The quality of the calibration is assumed to

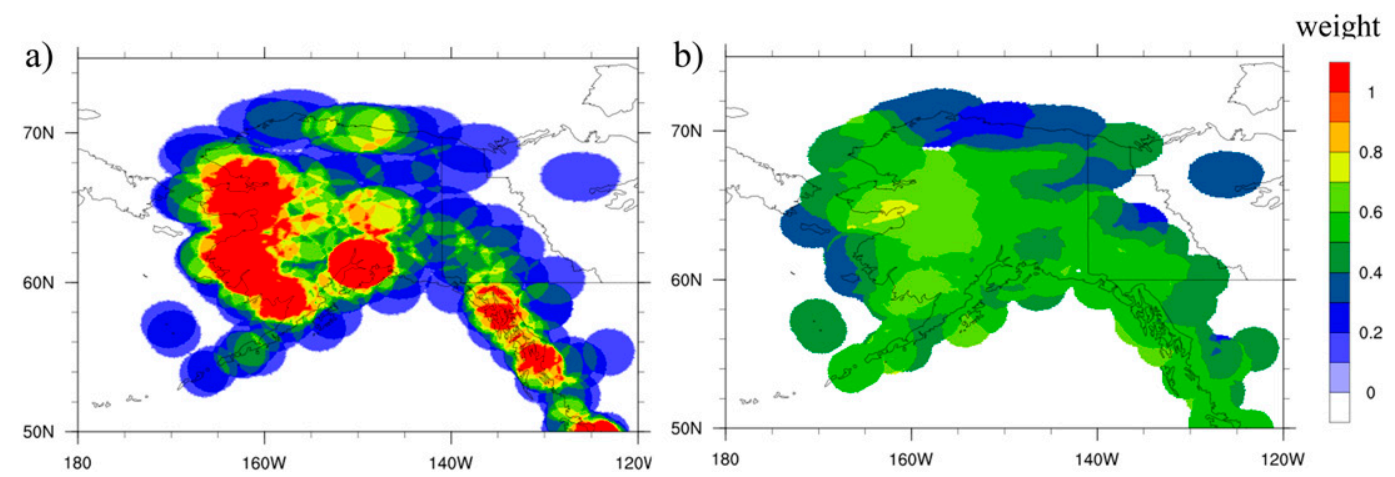

FIG. 9. Example of weights used to combine raw and calibrated model fields as derived from (a) the number of tiles term and (b) correlation term for ceiling heights in Eq. (3) for January 2019. 
a)

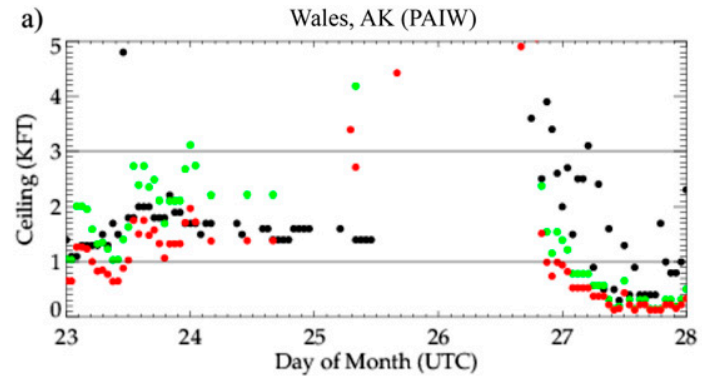

b)

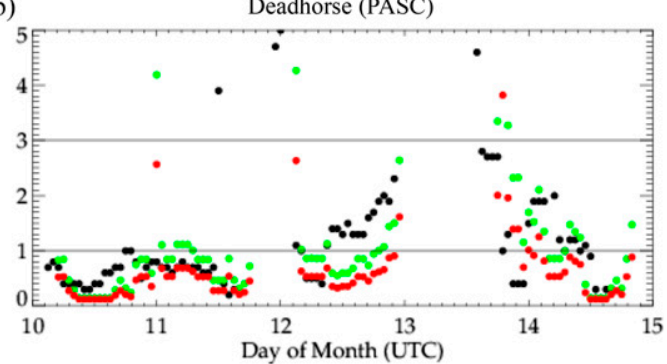

FIG. 10. Time series of observed (black), raw model (red), and calibrated model (green) 2-h ceiling heights forecasts for (a) Wales, near Nome, AK (PAIW), and (b) Deadhorse, AK (PASC), for selected 5-day periods in June 2019. The IFR and MVFR thresholds are indicated by the horizontal lines.

be function of the density of surface met stations surrounding a model grid point and the mean correlation between the observation and model values obtained at stations nearby. The calibrated value is weighted more in areas with a good density of observations and where correlations are highest. The final calibrated value $F_{\text {cal }}$ is obtained using a weighted average of the raw value $F_{\text {raw }}$ and the calibrated value obtained directly from the look up table $F_{\text {cal }}$, following:

$$
F_{\mathrm{cal}}=w_{\mathrm{cal}} F_{\mathrm{cal}_{0}}+\left(1-w_{\mathrm{cal}}\right) F_{\mathrm{raw}},
$$

where the weight $w_{\text {cal }}$ is a function of the number of stations $N_{s}$ within $200 \mathrm{~km}$ of a given model grid point and the mean correlation between observations and model forecasts obtained from stations within $200 \mathrm{~km}$ $\left\langle r_{s}\right\rangle$ following:

$$
w_{\text {cal }}=0.5\left\{\max \left(1, N_{s} / 8\right)+\left[\max \left(0,\left\langle r_{s}\right\rangle\right)\right]\right\} .
$$

The Spearman ranked correlation is used here because it is less sensitive to outliers (i.e., instances in which one of the two datasets is unlimited while the other indicate a restricting event; Wilks 2011). This weight will vary with time depending on the number

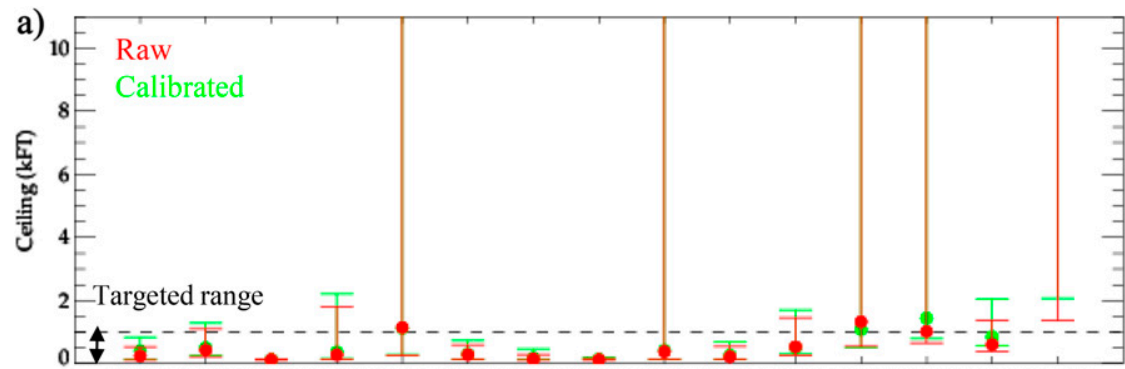

PASC PABR PAPOPAOMPAKP PAKHPAAD PAIW PAII PAPB PAKN PAIG PFKWPACM PALG Station

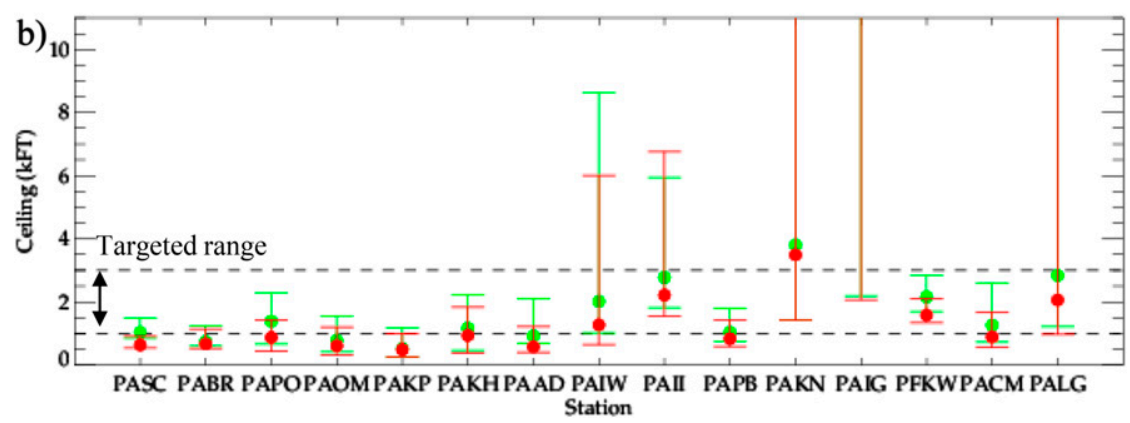

FIG. 11. Box-and-whisker plots showing interquartile range of model (raw in red and calibrated in green) ceiling height values for an observed category (target range) of (a) IFR and (b) MVFR obtained for 15 surface met stations across Alaska for the period 1-30 Jun 2019. The median value is denoted by a filled circle while the IQR is given by the error bars. The 75th percentile value occasionally lies outside the plotting range. 

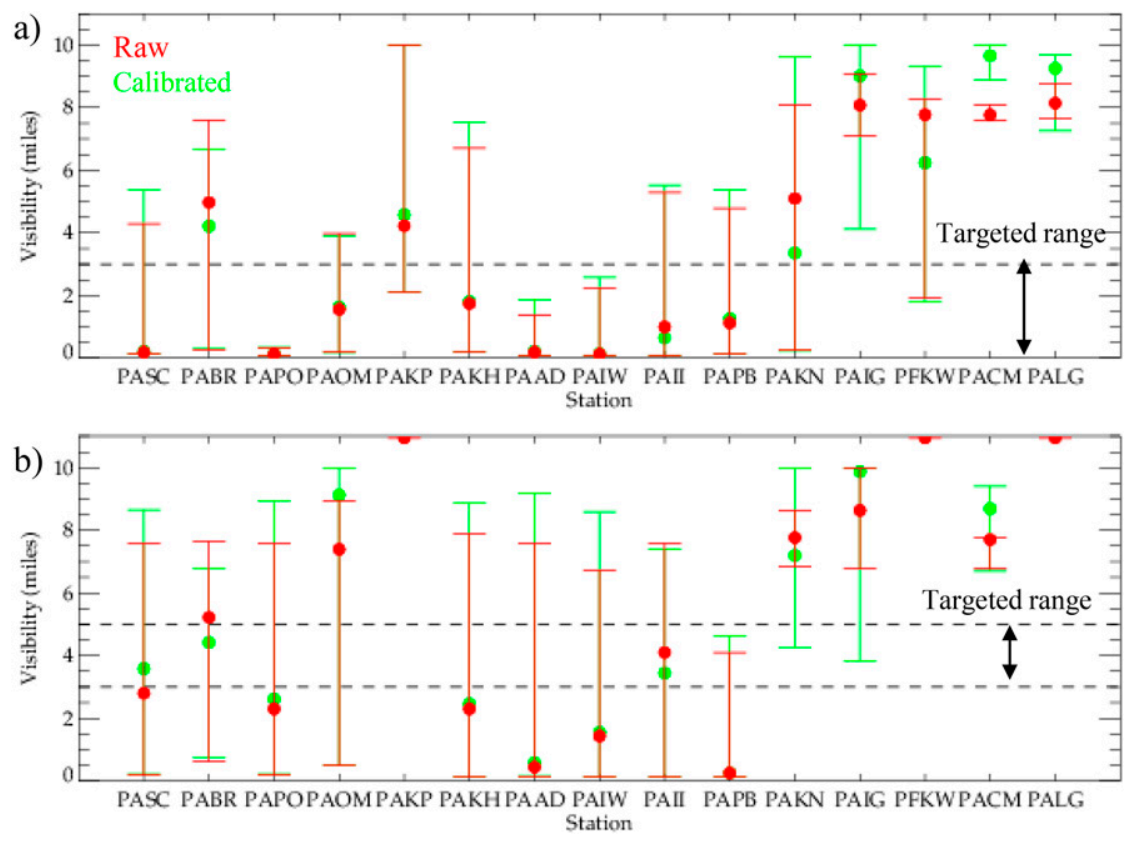

FIG. 12. As in Fig. 9, but for visibility. A value of 11 indicates sample size for the observed category was too small to generate a distribution of values.

of stations with an adequate sample size and the correlation between the model and observations over the last 30 days. An example of how the two terms of the weights equation vary across Alaska in winter is shown in Fig. 9. In terms of station coverage, the calibration is weighted most over southwestern Alaska, Anchorage and vicinity, and along the southeast panhandle. The correlation term for ceilings produces lower weights along the North Slope and higher weights across western Alaska where the model is best correlated with the observations. Note that the correlation term for visibility will differ from that found for ceiling heights.

Examples of how the calibration impacts the 2-h ceiling height forecasts are shown in Fig. 10 for 5-day periods from two surface met stations located in different coastal airports that may be characterized as having relatively flat terrain. In both examples, the raw 2-h ceiling height forecasts tended to be too low. The calibration generally increases the raw model values toward the observations with several of the raw model IFR ceiling heights being correctly shifted into the MVFR category. This is particularly evident during day 23 at Wales and days 12 and 14 at Deadhorse. While the calibration generally reduces the bias for both cases, there are short periods when the calibration overcorrects resulting in ceiling heights that are too high (e.g., Deadhorse, day 11). These short-period overcorrections tend to be much less frequent than the periods when the calibration reduces the bias.

TABLE 3. Disposition of median raw and calibrated forecast values for a given observed flight rule category for June 2019.

\begin{tabular}{|c|c|c|c|c|c|c|c|}
\hline $\begin{array}{l}\text { Observed } \\
\text { category }\end{array}$ & $\begin{array}{c}\text { Raw } \\
\text { below } \\
\text { category }\end{array}$ & $\begin{array}{l}\text { Calibration } \\
\text { reduces } \\
\text { underforecast }\end{array}$ & $\begin{array}{c}\text { Raw } \\
\text { inside } \\
\text { category }\end{array}$ & $\begin{array}{c}\text { Calibration } \\
\text { shifts median } \\
\text { outside category }\end{array}$ & $\begin{array}{c}\text { Raw } \\
\text { above } \\
\text { category }\end{array}$ & $\begin{array}{l}\text { Calibration } \\
\text { reduces } \\
\text { overforecast }\end{array}$ & $N$ stations $^{\mathrm{a}}$ \\
\hline & & & & Ceiling & & & \\
\hline IFR & - & - & 51 & 2 & 13 & 7 & 64 \\
\hline \multirow[t]{2}{*}{ MVFR } & 42 & 39 & 51 & 3 & 11 & 9 & 104 \\
\hline & & & & Visibility & & & \\
\hline IFR & - & - & 25 & 0 & 30 & 17 & 55 \\
\hline MVFR & 17 & 13 & 2 & 0 & 17 & 1 & 36 \\
\hline
\end{tabular}

${ }^{\mathrm{a}}$ Evaluation performed only for stations with at least $5 \%$ observed frequency of occurrence in a given category. 
TABLE 4. Contingency table for verification of four-category predictions. Bold font indicates summation across all indices.

\begin{tabular}{|c|c|c|c|c|c|c|c|c|c|c|c|}
\hline \multirow[b]{2}{*}{ Fcst } & \multicolumn{4}{|c|}{ Observed } & \multicolumn{7}{|c|}{ Terms of Heidke skill score for three categories } \\
\hline & $O_{1}$ & $\mathrm{O}_{2}$ & $\mathrm{O}_{3}$ & $\mathrm{O}_{4}$ & $\sum F$ & & VFR & & MVFR & & IFR \\
\hline$F_{1}$ & $r$ & $s$ & $t_{1}$ & $t_{2}$ & $\sum F_{1}$ & & & & & $a=r$ & $b=s+\mathbf{t}$ \\
\hline$F_{2}$ & $u$ & $v$ & $w_{1}$ & $w_{2}$ & $\bar{\sum} F_{2}$ & & & $a=v$ & $b=u+\mathbf{w}$ & $c=u+\mathbf{x}$ & $d=v+\mathbf{w}+\mathbf{y}+\mathbf{z}$ \\
\hline$F_{3}$ & $x_{1}$ & $y_{1}$ & $z_{1}$ & $z_{2}$ & $\bar{\sum} F_{3}$ & $a=\mathbf{z}$ & $b=\mathbf{x}+\mathbf{y}$ & $c=t+w$ & $d=r+\mathbf{t}+\mathbf{x}+\mathbf{z}$ & & \\
\hline $\begin{array}{c}F_{4} \\
\sum O\end{array}$ & $\begin{array}{c}x_{2} \\
\sum O_{1}\end{array}$ & $\begin{array}{c}y_{2} \\
\sum O_{2}\end{array}$ & $\sum^{z_{3}} O_{3}$ & $\stackrel{z_{4}}{\sum O_{4}}$ & $\bar{\Sigma} F_{4}$ & $c=\mathbf{t}+\mathbf{w}$ & $d=r+s+u+v$ & & & & \\
\hline
\end{tabular}

These two examples are representative of the overall performance of the algorithm that is discussed in detail below.

\section{Evaluation of bias correction algorithm}

The bias correction algorithm is using data collected in January and June of 2019. The performance is assessed for three flight rule categories for both ceiling and visibility: LIFR + IFR combined, MVFR, and VFR conditions (see Table 1) using two different techniques. Note that the LIFR and IFR categories were combined in order to produce an adequate sample size for the evaluation, since LIFR conditions occurred less than $1 \%$ of the time for both ceiling and visibility across all of Alaska.

The first assessment technique focuses on how the calibration algorithm changes the distribution of modeled ceiling and visibility values when conditionally sampled for observed categories of IFR and MVFR conditions. Note that the impact of calibration on distribution of model values when VFR conditions were observed is very small and therefore is not shown. This evaluation technique captures the statistical impact of the calibration algorithm at each station location. The spread of the distribution of model values is denoted by the interquartile range (IQR), which is indicated by bar and whiskers symbols (Figs. 11 and 12). As a guide to reading these plots, a perfect forecast would have its IQR lie completely within the target range of a given flight rule category. Whiskers that extend above the targeted range are indicative of event misses while those that lie below the targeted category are considered to be false alarms in which the model indicates a more restrictive hazard than was observed.

In general, the RAPv4 performed well when IFR ceilings were observed (Fig. 11). The median raw forecasted ceiling heights obtained when IFR ceilings were observed within or very near the targeted range of $0-1000 \mathrm{ft}$ for all but three of the stations shown. In fact, even the 75 th percentile values lie within the targeted IFR range at nearly half of the stations. The range of agreement shown is fairly representative of all stations that had an adequate sample size of observed IFR instances. Of the 64 station locations that experienced IFR conditions more than $5 \%$ of the time, the median raw model ceiling height fell within the targeted range at 51 of the locations (Table 3). While the calibration tends to increase the modeled IFR ceiling height values, these increases were generally small as indicated by the small upward shifts in the median and 75th percentile values. In fact, the calibration maintained most (all but two) of the median ceiling height values within the targeted IFR range (Table 3). At 13 of the stations the median height of the raw forecast was above the IFR target range [e.g., Igiugig (PAIG), Kwethluk (PFKW) in Fig. 11]. The calibration improved the median value at more than half of these station locations by decreasing the median ceiling height at these locations (Table 3).

TABLE 5. Four category contingency table counts for raw model ceiling heights from June 2019.

\begin{tabular}{|c|c|c|c|c|c|c|}
\hline \multirow[b]{2}{*}{ Forecast categories } & \multicolumn{4}{|c|}{ Observed categories } & \multirow[b]{2}{*}{$\sum F$} & \multirow[b]{2}{*}{ Forecast frequency } \\
\hline & $O_{1}$ & $\mathrm{O}_{2}$ & $\mathrm{O}_{3}$ & $\mathrm{O}_{4}$ & & \\
\hline$F_{1}$ & 7951 & 4870 & 1106 & 2846 & 16773 & $20.6 \%$ \\
\hline$F_{2}$ & 912 & 3441 & 2155 & 2114 & 8622 & $10.6 \%$ \\
\hline$F_{3}$ & 88 & 281 & 727 & 1541 & 2637 & $3.2 \%$ \\
\hline$F_{4}$ & 1709 & 2526 & 4251 & 44537 & 53023 & $65.4 \%$ \\
\hline$\sum O$ & 10660 & 11118 & 8239 & 51038 & 81055 & \\
\hline Obs frequency & $13.1 \%$ & $13.7 \%$ & $10.1 \%$ & $63.0 \%$ & & \\
\hline
\end{tabular}


TABLE 6. Change in contingency table counts (calibrated - raw) model ceiling heights from June 2019.

\begin{tabular}{|c|c|c|c|c|c|c|}
\hline \multirow{2}{*}{$\begin{array}{c}\text { Forecast } \\
\text { categories }\end{array}$} & \multicolumn{4}{|c|}{ Observed categories } & \multirow[b]{2}{*}{$\sum F$} & \multirow{2}{*}{$\begin{array}{l}\text { Calibratec } \\
\text { frequency }\end{array}$} \\
\hline & $O_{1}$ & $\mathrm{O}_{2}$ & $\mathrm{O}_{3}$ & $\mathrm{O}_{4}$ & & \\
\hline$F_{1}$ & -371 & -897 & -240 & -260 & -1773 & $18.5 \%$ \\
\hline$F_{2}$ & 311 & 538 & -337 & -306 & 206 & $10.9 \%$ \\
\hline$F_{3}$ & 71 & 388 & 558 & 603 & 1620 & $5.3 \%$ \\
\hline$F_{4}$ & -6 & -29 & 19 & -37 & -53 & $65.3 \%$ \\
\hline$\sum O$ & 0 & 0 & 0 & 0 & 0 & \\
\hline
\end{tabular}

While calibration increases the 75th percentile ceiling height values obtained when IFR ceilings were observed (see examples in Fig. 11), this impact is greatly outweighed by the improvements afforded by calibration when MVFR ceiling heights were observed (Fig. 10 and Table 3). This is illustrated at several stations shown in Fig. 11 [e.g., PASC, Point Hope (PAPO), Point Thomson (PAAD)] where the median value of the raw ceiling heights (and much of interquartile range) falls below the MVFR threshold. In each of these cases, the calibration increased the median value toward the targeted MVFR range. In fact, of the 42 stations where the raw model had median ceiling heights below the target MVFR range, 39 were moved closer to the target range (Table 3 ) with the median value being increased into the correct category at 18 stations. As will be discussed further below, this upward shift of the IQR when MVFR is observed results in a dramatic reduction in the number of IFR false alarms. At King Salmon (PAKN), the raw forecasts of the MVFR category were slightly degraded by the calibration with the median calibrated value experiencing a small shift away from the MVFR range (Fig. 11). However, these negative impacts were generally small, and not very common (only 5 out of 104 station locations in Table 3).

The same evaluation method is applied to raw and calibrated model visibility as well. In general, the 25 th and 75 th percentile values for raw modeled visibility tend to lie outside the targeted range much more often than was found for the raw modeled ceiling heights (Fig. 12). This indicates that the model is generally less skillful at predicting visibility restrictions than it is at predicting ceiling height constraints. This is clearly seen in the number of 75 th percentile raw model values that lie above the targeted range for both the IFR and MVFR categories. That is, the raw model is less likely to detect visibility-limiting events than ceiling-limiting events. The reduced skill of the raw model for visibility limits the skill of the calibration algorithm. Because of this increased model error, the calibration tends to increase the IQR for both IFR and MVFR categories are observed (Fig. 12). However, despite this broadening of the distribution of visibility values given an observed event, the calibration algorithm notably improves the median value at several stations (e.g., PASC, PABR, PAPO, and PAKN). Results at PABR and PAKN show dramatic downward shifts in their median values in both the IFR and MVFR categories indicating that the calibration is reducing the underforecasting bias. In fact, the calibration improves then median value for more than $50 \%$ of the cases when the raw median value was above the IFR range and never shifts a median value out of the IFR range.

When MVFR was observed, the median visibility from the raw model was split evenly, with half the values falling below the target range and half above the targeted range (Fig. 12 and Table 3). The calibration generally improved visibility values for cases when the raw median value fell below the targeted range but performed poorly when the raw model visibilities were greater than the MVFR target range such as at Nome (PAOM, see Fig. 12). In this case, the calibration acts to degrade the visibility forecasts, by increasing the median value away from the target range. This degradation occurred at locations where the model had difficultly capturing the conditions that lead to MVFR visibilities (e.g., missed light precipitation events, haze; e.g., see the time series for PAOM shown in Fig. 2).

TABLE 7. Four-category contingency table counts for raw model ceiling heights from January 2019.

\begin{tabular}{|c|c|c|c|c|c|c|}
\hline \multirow[b]{2}{*}{ Forecast categories } & \multicolumn{4}{|c|}{ Observed categories } & \multirow[b]{2}{*}{$\sum F$} & \multirow[b]{2}{*}{ Forecast frequency } \\
\hline & $O_{1}$ & $\mathrm{O}_{2}$ & $\mathrm{O}_{3}$ & $\mathrm{O}_{4}$ & & \\
\hline$F_{1}$ & 4755 & 7899 & 2441 & 3651 & 18746 & $23.3 \%$ \\
\hline$F_{2}$ & 796 & 5019 & 3166 & 2434 & 11415 & $14.2 \%$ \\
\hline$F_{3}$ & 142 & 830 & 942 & 1123 & 3037 & $3.8 \%$ \\
\hline$F_{4}$ & 1645 & 3593 & 4552 & 37450 & 47250 & $58.7 \%$ \\
\hline$\sum O$ & 7348 & 17341 & 11101 & 44658 & 80448 & \\
\hline Obs frequency & $9.1 \%$ & $21.6 \%$ & $13.8 \%$ & $55.5 \%$ & & \\
\hline
\end{tabular}


TABLE 8. Change in contingency table counts (calibrated - raw) model ceiling heights from January 2019.

\begin{tabular}{|c|c|c|c|c|c|c|}
\hline \multirow{2}{*}{$\begin{array}{c}\text { Forecast } \\
\text { categories }\end{array}$} & \multicolumn{4}{|c|}{ Observed categories } & \multirow[b]{2}{*}{$\sum F$} & \multirow{2}{*}{$\begin{array}{l}\text { Calibrated } \\
\text { frequency }\end{array}$} \\
\hline & $O_{1}$ & $\mathrm{O}_{2}$ & $\mathrm{O}_{3}$ & $\mathrm{O}_{4}$ & & \\
\hline$F_{1}$ & -320 & -869 & -260 & -357 & -1806 & $21.1 \%$ \\
\hline$F_{2}$ & 307 & 765 & 192 & 333 & 1597 & $16.2 \%$ \\
\hline$F_{3}$ & 23 & 121 & 70 & 41 & 255 & $4.1 \%$ \\
\hline$F_{4}$ & -10 & -17 & -2 & -17 & -46 & $58.6 \%$ \\
\hline$\sum O$ & 0 & 0 & 0 & 0 & 0 & \\
\hline
\end{tabular}

In addition to the statistical assessment described above, the performance of the calibration algorithm is also evaluated using direct comparison of modeled and observed aviation-limiting events. A multiplecategory contingency table is produced by using pairs of observed and modeled values that are coincident in time for each station. Table 4 provides an example of a four-category contingency table. The categories are given by Table 1 where LIFR and IFR are combined into a single IFR category and a near MVFR category has been added. Only data from stations with an adequate number of events are included in this evaluation. Four-category contingency tables are developed for both ceiling and visibility for data collected during January and June 2019 (Tables 5, 7, 9, and 11). Each four-category contingency table has 16 possible outcomes. Values that lie along the diagonal represent hits while those that are off by two or more categories, are indicative of either complete misses (lower-left corner of table) or false alarms (upper right). The difference in the counts obtained for raw and calibrated forecasts is also given in Tables $6,8,10$, and 12 . Ideally, one would like to see positive counts along the diagonal and negative counts everywhere else. The bottom row of Tables 5, 7, 9, and 11 indicates the observed frequencies computed from all available stations while the rightmost column gives the forecasted frequencies.

In June, the observations indicate an equal mix of IFR and MVFR ceilings that occurred a total of $27 \%$ of the time. The model predicted IFR conditions twice as often as MVFR. This overforecasting of IFR conditions is evident in Table 5 (cell: $F_{1}, O_{2}$ ), which indicates that the model tended to predict IFR ceilings when MVFR ceilings were observed. In fact, the model predicted IFR ceiling heights nearly $60 \%$ more often than observed with $25 \%$ (4870) of these predictions being off by just one category. This ceiling height bias is improved by the calibration algorithm with nearly $900(18 \%)$ instances being removed from this contingency box (Table $6 ; F_{1}, O_{2}$ ). Overall, the calibration algorithm reduces IFR false alarms by $16 \%$ while reducing hits by only $4 \%$. At the same time, the number MVFR hits is improved by $538(15 \%)$ and the number of MVFR false alarms is reduced by $642(15 \%)$. Similar improvements are evident in the near-MVFR category. These improvements result in a notable reduction in the IFR overforecasting bias (Tables 6 and 8).

In January, the observations indicate that MVFR ceiling heights are most common across Alaska while the model has IFR being the most common category. In fact, the model predicted more the twice as many IFR ceilings events than were observed (Table 7). Again, the main impact of calibration is to dramatically reduce the number of IFR ceiling false alarms while greatly increasing the number of MVFR ceiling hits (Table 7, cell: $\mathrm{F}_{2}, \mathrm{O}_{2}$ ). The reduction in IFR false alarms does come with the penalty of reducing the number of IFR ceiling hits as well. However, in terms of overall skill (see below), this reduction in IFR hits is more than offset by the reduction in IFR false alarms and increase in MVFR hits.

Moving on to visibility (Tables 9-12), the observations indicate that the predominant conditions are either IFR $(12 \%)$ or VFR $(82 \%)$ in both seasons. The model captures this observed pattern but tends to overforecast the frequency of IFR visibilities (17\%). Note that only a limited number of stations observed enough visibilityrestricting events to be evaluated. Thus, the number of corrections is rather small, with the main changes being a slight increase in IFR hits and a slight reduction

TABLE 9. Four category contingency table counts for raw model visibility from June 2019 using 45 stations.

\begin{tabular}{|c|c|c|c|c|c|c|}
\hline \multirow[b]{2}{*}{ Forecast categories } & \multicolumn{4}{|c|}{ Observed categories } & \multirow[b]{2}{*}{$\sum F$} & \multirow[b]{2}{*}{ Forecast frequency } \\
\hline & $O_{1}$ & $\mathrm{O}_{2}$ & $\mathrm{O}_{3}$ & $\mathrm{O}_{4}$ & & \\
\hline$F_{1}$ & 2019 & 468 & 180 & 2307 & 4974 & $16.8 \%$ \\
\hline$F_{2}$ & 324 & 85 & 41 & 1108 & 1558 & $5.3 \%$ \\
\hline$F_{3}$ & 121 & 47 & 14 & 383 & 565 & $1.9 \%$ \\
\hline$F_{4}$ & 954 & 467 & 249 & 20759 & 22429 & $76.0 \%$ \\
\hline$\sum O$ & 3418 & 1067 & 484 & 24557 & 29526 & \\
\hline Obs frequency & $11.6 \%$ & $3.6 \%$ & $1.6 \%$ & $83.2 \%$ & & \\
\hline
\end{tabular}


TABLE 10. Change in contingency table counts (calibrated - raw) model visibility from June 2019 using 45 stations.

\begin{tabular}{|c|c|c|c|c|c|c|}
\hline \multirow{2}{*}{$\begin{array}{c}\text { Forecast } \\
\text { categories }\end{array}$} & \multicolumn{4}{|c|}{ Observed categories } & \multirow[b]{2}{*}{$\sum F$} & \multirow{2}{*}{$\begin{array}{l}\text { Calibrated } \\
\text { frequency }\end{array}$} \\
\hline & $O_{1}$ & $\mathrm{O}_{2}$ & $\mathrm{O}_{3}$ & $O_{4}$ & & \\
\hline$F_{1}$ & 23 & -4 & 0 & -44 & -25 & $16.7 \%$ \\
\hline$F_{2}$ & -45 & 1 & -5 & -148 & -197 & $4.6 \%$ \\
\hline$F_{3}$ & -18 & 0 & 3 & 75 & 60 & $2.1 \%$ \\
\hline$F_{4}$ & 40 & 3 & 2 & 117 & 162 & $76.5 \%$ \\
\hline$\sum O$ & 0 & 0 & 0 & 0 & 0 & \\
\hline
\end{tabular}

in the number of IFR and MVFR false alarms in June with the calibrated model MVFR showing a $0.7 \%$ reduction in the overforecasting bias. In January, 64 stations qualified as having enough visibility-restricting events (Tables 11 and 12). The observed frequency of IFR events was the same as in June (i.e., $12 \%$ ) but the model showed much less skill at predicting IFR visibilities with $45 \%$ of the IFR forecasts being false alarms (cell: $F_{1}, O_{4}$ ) and $45 \%$ of the observed IFR conditions being completely missed (cell: $F_{4}, O_{1}$ ). Due to lower skill in the raw model forecasts in predicting visibilities in January, the calibration algorithm resulted in only minor increases in POD of IFR conditions and a slight reduction in the MVFR false alarms.

The net impact of the calibration on skill can be quantified using the Heidke skill score (HSS), which is computed from the contingency tables following:

$$
\mathrm{HSS}=\frac{2(a d-b c)}{[(a+c)(c+d)+(a+b)(b+d)]},
$$

where each of the variables in this equation $(a, b, c, d)$ are given by expressions in Table 4 . The HSS ranges from negative infinity to one and measures the skill relative to that which would be obtained by random chance. Values of the HSS greater than zero are indicative of forecasts that are more skillful than a random set of forecasts (Wilks 2011). The HSS of the calibrated model is greater than that obtained for the raw model for nearly all categories and both seasons. The biggest improvements are evident in the IFR and MVFR ceiling height predictions in June (Table 13). Lesser improvements in HSS were obtained for visibility. Using a boot strap resampling method it was found that all of the improvements obtained with calibration were statistically significant except for the small improvement in MVFR visibilities obtained in January.

\section{Discussion and conclusions}

The 2-h forecasts from the RAPv4 captured over $65 \%$ of the IFR ceilings at the expense of a bias exceeding $250 \%$. Biases in the 2 -h forecasts of ceiling and visibility obtained from RAPv 4 were found to vary both seasonally and spatially. In winter, the RAPv4 tended to generate low ceilings too often throughout Alaska with peak biases occurring along the North Slope of Alaska. In summer, low bias in the RAPv4 ceiling heights was confined to coastal regions and across the Aleutian Islands. The RAPv4 was less skillful at predicting visibility constraints, capturing less than $50 \%$ of the observed IFR visibility events in both seasons. A portion of this forecast error was due to the visibility diagnostic lacking a treatment for the impact of blowing snow in winter, and the lack of a treatment of black soot from forest fires in summer. It is noted that future releases of both the RAP and HRRR will include a treatment of smoke from forest fires in the visibility calculation that should reduce this bias.

The calibration algorithm presented in this paper uses quantile matching to remove mean biases from model forecasts. It was applied to the RAPv4 model and shown to reduce biases and improve the overall skill of 2-h forecasts of both ceiling and visibility in both winter and summer. It is expected that the technique would result in similar improvements at other forecast lead times and in other mesoscale forecast models such as the HRRR. While the calibration algorithm cannot generate or remove cloud layers or

TABLE 11. Four category contingency table counts for raw model visibility from January 2019 using data from 64 stations.

\begin{tabular}{ccccccc}
\hline \hline & \multicolumn{9}{c}{ Observed categories } & & \\
\cline { 2 - 6 } Forecast categories & $O_{1}$ & $O_{2}$ & $O_{3}$ & $O_{4}$ & & Forecast frequency \\
\hline$F_{1}$ & 2023 & 685 & 296 & 2498 & 5502 & $12.5 \%$ \\
$F_{2}$ & 562 & 213 & 108 & 1366 & 2249 & $5.1 \%$ \\
$F_{3}$ & 251 & 104 & 54 & 739 & 1148 & $2.6 \%$ \\
$F_{4} O$ & 2586 & 1249 & 659 & 30544 & 35038 & $79.7 \%$ \\
Obs frequency & 5422 & 2251 & 1117 & 35147 & 43937 & \\
\hline
\end{tabular}


TABLE 12. Change in contingency table counts (calibrated raw) for model visibility from January 2019 using data from 64 stations.

\begin{tabular}{|c|c|c|c|c|c|c|}
\hline \multirow{2}{*}{$\begin{array}{c}\begin{array}{c}\text { Forecast } \\
\text { categories }\end{array} \\
\end{array}$} & \multicolumn{4}{|c|}{ Observed categories } & \multirow[b]{2}{*}{$\sum F$} & \multirow{2}{*}{$\begin{array}{l}\text { Calibrated } \\
\text { frequency }\end{array}$} \\
\hline & $O_{1}$ & $\mathrm{O}_{2}$ & $\mathrm{O}_{3}$ & $O_{4}$ & & \\
\hline$F_{1}$ & 13 & -2 & -6 & -46 & -41 & $12.4 \%$ \\
\hline$F_{2}$ & 69 & 21 & 10 & 159 & 259 & $5.7 \%$ \\
\hline$F_{3}$ & 16 & 11 & -1 & 41 & 67 & $2.8 \%$ \\
\hline$F_{4}$ & -98 & -30 & -3 & -154 & -285 & $79.1 \%$ \\
\hline$\sum O$ & 0 & 0 & 0 & 0 & 0 & \\
\hline
\end{tabular}

visibility restrictions, it can adjust the modeled ceiling and visibility values enough to change the flight rule category of the event. Because the algorithm relies on the model to have some indication of a flight rules limiting event, it works best when the model tends to overforecast the frequencies of occurrence of IFR and MVFR conditions.

Observational data quality and the representativeness of observations made at a given station can impact the performance of the calibration technique. The algorithm assumes that adequate data quality measures are in place. The representativeness of an observation also needs to be considered, especially in regions of complex terrain. Differences between the elevation of the surface met station and the terrain height of the closest corresponding model grid point can be large. In Alaska, the surface met stations tend to be at much lower elevations than the terrain height of the nearest model grid point (Fig. 13). In fact, there are 15 stations where the model terrain height is more than $500 \mathrm{ft}$ above the elevation of the surface met station. This will tend to make the model ceiling heights lower than those observed at the nearest station. Consistent with this issue, the model overforecasted the frequency of IFR $(<1000 \mathrm{ft})$ ceiling heights at all 15 of these stations for data collected

TABLE 13. Heidke skill scores using data from all stations that had observation vs model correlations greater than 0.35 . Bold font indicates categories for which calibration significantly improved the skill.

\begin{tabular}{llcccccc}
\hline \hline & \multicolumn{3}{c}{ Raw } & & \multicolumn{3}{c}{ Calibrated } \\
\cline { 2 - 3 } \cline { 7 - 8 } & IFR & MVFR & VFR & & IFR & MVFR & VFR \\
\hline Ceilings & & & & & & \\
$\quad$ January & 0.268 & 0.215 & 0.507 & $\mathbf{0 . 2 7 3}$ & $\mathbf{0 . 2 4 1}$ & 0.505 \\
June & 0.499 & 0.260 & 0.618 & $\mathbf{0 . 5 1 6}$ & $\mathbf{0 . 3 1 6}$ & $\mathbf{0 . 6 3 0}$ \\
Visibility & & & & & & \\
$\quad$ January & 0.281 & 0.046 & 0.335 & $\mathbf{0 . 2 8 7}$ & 0.047 & $\mathbf{0 . 3 4 1}$ \\
June & 0.399 & 0.023 & 0.421 & $\mathbf{0 . 4 0 7}$ & $\mathbf{0 . 0 3 2}$ & $\mathbf{0 . 4 3 1}$ \\
\hline
\end{tabular}

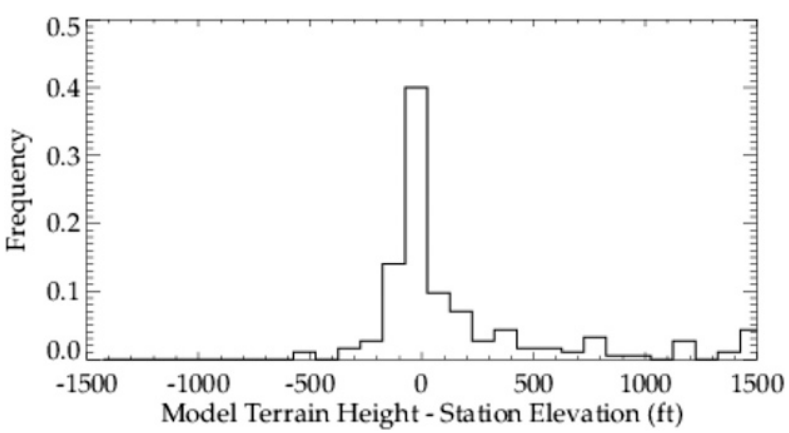

FIG. 13. Distribution of terrain height differences as defined as the model terrain height at the grid point nearest to the observation site minus the elevation of the surface met station. All differences greater than $1500 \mathrm{ft}$ are accumulated in the rightmost bin.

during June 2019. Nonetheless, the calibration algorithm implicitly reduces this terrain height offset effect from the model forecasted ceiling heights at the station location. Future work could evaluate the how the radius of influence of the calibration might be modified to be a function of the difference between the model terrain height and surface met station elevation. This could be done, using a high-resolution elevation map and performing data denial experiments in regions where there is a good density of observations and complex terrain to ascertain what this spatial weighting might look like (e.g., Alaskan Panhandle).

As modeling systems move toward higher resolutions, the need for calibration will still exist. The calibration algorithm method presented here is easily extendable to higher-resolution models. The current calibration technique can serve as a benchmark for future techniques to improve upon. It is expected that machine learning techniques could also be developed to further improve modeled ceiling and visibility forecasts by taking into account multiple predictor fields including modeled atmospheric state variables (e.g., relative humidity, wind speed and direction), terrain variability, proximity to open water or sea ice, and climatological information. These efforts to improve the depiction of aviation hazards in data-sparse regions are needed to further increase the safety of general aviation in Alaska and other data-sparse regions of the world.

Acknowledgments. This research has been conducted in response to requirements of the Federal Aviation Administration (FAA) and has been supplemented by funding provided by the National Science Foundation (NSF) to NCAR. The views expressed are those of the authors and do not necessarily represent the official policy or position of either the FAA or NSF. Suggestions and comments provided by Anders Jensen and Tammy 
Weckwerth of NCAR and the anonymous reviewers helped to improve the manuscript.

\section{REFERENCES}

Aarons, R. N., 2018: Alaskan CFIT Continues to Kill. Business and Commercial Aviation, 5 pp.

Alexander, C., and Coauthors, 2018: WRF-ARW Research to Operations Update: The Rapid-Refresh (RAP) version 4, High-Resolution Rapid Refresh (HRRR) version 3 and convection-allowing ensemble prediction. 18th Annual WRF Users Workshop, Boulder, CO, NOAA/ESRL/Global Systems Division, 34 pp., https://ruc.noaa.gov/ruc/ppt_pres/Alexander_ WRFworkshop_2017_Final.pdf.

An, N., K. Wang, C. Zhou, and R. T. Pinker, 2017: Observed variability of cloud frequency and cloud-base height within $3600 \mathrm{~m}$ above the surface over the contiguous United States. J. Climate, 30, 3725-3742, https://doi.org/10.1175/JCLI-D-16-0559.1.

Barker, H. W., M. P. Jerg, T. Wehr, S. Kato, D. P. Donovan, and R. J. Hogan, 2011: A 3D cloud-construction algorithm for the EarthCARE satellite mission. Quart. J. Roy. Meteor. Soc., 137, 1042-1058, https://doi.org/10.1002/qj.824.

Benjamin, S. G., and Coauthors, 2016: A North American hourly assimilation and model forecast cycle: The Rapid Refresh. Mon. Wea. Rev., 144, 1669-1694, https://doi.org/10.1175/ MWR-D-15-0242.1.

Brehmer, E., 2017: Rare Alaska hearing probes causes for plane crashes. Alaska Journal of Commerce, 23 August 2017, https:// www.alaskajournal.com/2017-08-23/rare-alaska-hearing-probescauses-plane-crashes\#.WZ7qzyiGOUl.

Brunner, J., R. B. Pierce, and A. Lenzen, 2016: Development and validation of satellite-based estimates of surface visibility. Atmos. Meas. Tech., 9, 409-422, https://doi.org/10.5194/amt-9-409-2016.

Crosby, J. D., 2003: Visibility sensor accuracy: What is realistic? 12th Symp. on Meteorological Observations and Instrumentation, Long Beach, CA, Amer. Meteor. Soc., 15.5, https://ams.confex.com/ ams/annual2003/techprogram/paper_59024.htm.

Delle Monache, L., T. Nipen, Y. Liu, G. Roux, and R. Stull, 2011: Kalman filter and analog schemes to post process numerical weather predictions. Mon. Wea. Rev., 139, 3554-3570, https:// doi.org/10.1175/2011MWR3653.1.

De Pondeca, M. S. F. V., and Coauthors, 2011: The real-time mesoscale analysis at NOAA's National Centers for Environmental Prediction: Current status and development. Wea. Forecasting, 26, 593-612, https://doi.org/10.1175/WAF-D-10-05037.1.

Ghirardelli, J. E., and B. Glahn, 2010: The Meteorological Development Laboratory's aviation weather prediction system. Wea. Forecasting, 25, 1027-1051, https://doi.org/10.1175/ 2010WAF2222312.1.

Glahn, B., and J. Im, 2011: Algorithms for effective objective analysis of surface weather variables. 24th Conf. on Weather and Forecasting/20th Conf. on Numerical Weather Prediction, Seattle, WA, Amer. Meteor. Soc., J19.4, https://ams.confex.com/ ams/91Annual/webprogram/Paper179368.html.

_- A. D. Schnapp, J. E. Ghirardelli, and J. Im, 2017: A LAMP-HRRR MELD for improved aviation guidance. Wea. Forecasting, 32, 391-405, https://doi.org/10.1175/WAFD-16-0127.1.

Glahn, H. R., and D. A. Lowry, 1972: The use of model output statistics (MOS) in objective weather forecasting. J. Appl. Meteor., 11, 1203-1211, https://doi.org/10.1175/1520-0450(1972)011<1203: TUOMOS $>2.0 . C O ; 2$.
Grzywinski, C., and D. L. Sims, 2005: Alaska ceiling and visibility $(\mathrm{C} \& \mathrm{~V})$ users needs assessment Alaska pilot study. Proc. MiniConf. on Human Factors in Complex Sociotechnical Systems, Atlantic City, NJ, Human Factors and Ergonomics Soc., 5 pp.

Hallowell, R. G., M. P. Matthews, and P. A. Pisano, 2007: An automated visibility detection algorithm utilizing camera imagery. 23rd Conf. on Interactive Information Processing Systems (IIPS), San Antonio, TX, Amer. Meteor. Soc., 4A.7, https://ams.confex.com/ams/ 87ANNUAL/techprogram/paper_120107.htm.

Hopson, T., and P. J. Webster, 2010: A 1-10-day ensemble forecasting scheme for the major river basins of Bangladesh: Forecasting severe floods of 2003-07. J. Hydrometeor., 11, 618-641, https://doi.org/10.1175/2009JHM1006.1.

Hutchison, K. D., E. Wong, and S. C. Ou, 2006: Cloud base height retrieval during nighttime conditions with MODIS data. Int. J. Remote Sens., 27, 2847-2862, https://doi.org/ 10.1080/01431160500296800.

James, E. P., and Coauthors, 2019: Rapidly-updating highresolution predictions of smoke, visibility, and smokeweather interactions using satellite fire products within the Rapid Refresh and High-Resolution Rapid Refresh coupled with smoke (RAP/HRRR-smoke). 35th Conf. on Environmental Information Processing Technologies, Phoenix, AZ, Amer. Meteor. Soc, 4B.3, https://ams.confex.com/ams/ 2019Annual/meetingapp.cgi/Paper/353068.

Keller, D. L., and E. L. Kuchera, 2004: Model-output postprocessor algorithm development with interactive visualization software. Natl. Wea. Dig., 28, 47-53.

Kessner, A. L., J. Wang, R. C. Levy, and P. R. Colarco, 2013: Remote sensing of surface visibility from space: A look at the United States East Coast. Atmos. Environ., 81, 136-147, https://doi.org/10.1016/j.atmosenv.2013.08.050.

Klouda, N., C. Zervantain, G. W. Fauske, B. Cioni-Haywood, P. Gage, A. Enghirst, and L. Bower, 2018: Growth and obstacles in the aviation and aerospace sectors in Alaska. Emerging Sector Series: Aviation and Aerospace, https://www.commerce.alaska.gov/web/ ded/DEV/AlaskasEmergingSectorsReportSeries.aspx.

Matthews, M., and J. Colavito, 2017: Alaska C\&V Camera Imagery Analytics. Friends and Partners in Aviation Weather Meeting, Las Vegas, NV, Lincoln Laboratory, MIT, 12 pp., https:// ral.ucar.edu/sites/default/files/public/events/2017/friends-andpartners-in-aviation-weather/docs/matthews-presentation-v2114682.pdf.

McCorkle, T. A., J. D. Horel, A. A. Jacques, and T. Alcott, 2018: Evaluating the experimental High-Resolution Rapid RefreshAlaska modeling system using USArray observations. Wea. Forecasting, 33, 933-953, https://doi.org/10.1175/WAF-D-17-0155.1.

Minnis, P., and Coauthors, 2011: CERES Edition-2 cloud property retrievals using TRMM VIRS and Terra and Aqua MODIS data-Part I: Algorithms. IEEE Trans. Geosci. Remote Sens., 49, 4374-4400, https://doi.org/10.1109/TGRS.2011.2144601.

NOAA, 2017: Surface weather observations and reports. Federal Meteorological Handbook (FMH-1) Rep. FCMH1-2017, U.S. Department of Commerce/National Oceanic and Atmospheric Administration, 98 pp., https://www.ofcm.gov/ publications/fmh/FMH1/FMH1_2017.pdf.

Noh, Y.-J., and Coauthors, 2017: Cloud-base height estimation from VIIRS. Part II: A statistical algorithm based on A-train satellite data. J. Atmos. Oceanic Technol., 34, 585-598, https:// doi.org/10.1175/JTECH-D-16-0110.1.

NWS, 1998: Automated Surface Observing System (ASOS) user's guide. NOAA Rep., 61 pp, https://www.nws.noaa.gov/asos/ aum-toc.pdf. 
Rasmussen, R. M., J. Vivekanandan, J. Cole, B. Myers, and C. Masters, 1999: The estimation of snowfall rate using visibility. J. Appl. Meteor., 38, 1542-1563, https://doi.org/10.1175/ 1520-0450(1999)038<1542:TEOSRU>2.0.CO;2.

Rasp, S., and S. Lerch, 2018: Neural networks for post-processing ensemble weather forecasts. Mon. Wea. Rev., 146, 3885-3900, https://doi.org/10.1175/MWR-D-18-0187.1.

Skamarock, W. C., and J. B. Klemp, 2008: A time-split nonhydrostatic atmospheric model for weather research and forecasting applications. J. Comput. Phys., 227, 3465-3485, https://doi.org/10.1016/j.jcp.2007.01.037.

, and Coauthors, 2008: A description of the Advanced Research WRF version 3. NCAR Tech. Note NCAR/TN-475+STR, 113 pp., https://doi.org/10.5065/D68S4MVH.
Stoelinga, M. T., and T. T. Warner, 1999: Nonhydrostatic, meso-beta scale model simulations of cloud ceiling and visibility for an East Coast winter precipitation event. J. Appl. Meteor., 38, 385-404, https:// doi.org/10.1175/1520-0450(1999)038<0385:NMSMSO > 2.0.CO;2.

Weiss, M., and J. E. Ghirardelli, 2005: A summary of ceiling height and total sky cover short-term statistical forecasts in the Localized Aviation MOS Program (LAMP). Preprints, 21st Conf. on Weather Analysis and Forecasting/17th Conf. on Numerical Weather Prediction, Washington, DC, Amer. Meteor. Soc., 13B.6, https://ams.confex.com/ams/WAFNWP34BC/ techprogram/paper_95121.htm.

Wilks, D. S., 2011: Statistical Methods in the Atmospheric Sciences. 3rd ed. International Geophysics Series, Vol. 100, Academic Press, 704 pp. 